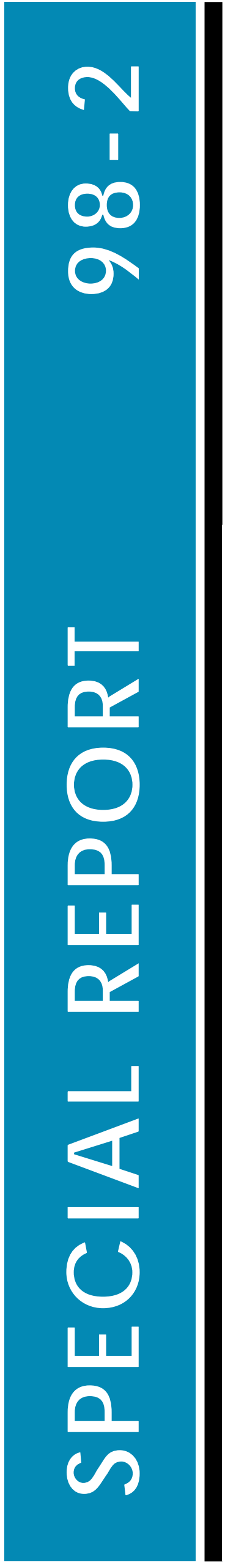

\title{
Soil Moisture Determinations Using Capacitance Probe Methodology
}

Ronald T. Atkins, Timothy Pangbum, Roy E. Bates, and Bruce E. Brockett 
Abstract: Determining soil moisture content by measuring the dielectric constant of the soil is not a new concept. However, determining the dielectric constant by measuring capacitance directly rather than through the use of time domain reflectometry (TDR) systems is a relatively new approach to soil moisture measurements. A unique probe assembly and a readout device that measures voltage drop and phase shift were developed and used for direct capacitance measurements. The capacitance measurement was calibrated using known capacitors and resistors. Soil moisture measurements were calibrated by adding known amounts of distilled water to dry soil enclosed in a known volume. The effect of salinity on the measurement technique was evaluated. Once calibration had been accomplished, actual soil moisture measurements at three test depths through an entire winter's freezethaw cycle demonstrated the feasibility of using this capacitance measurement system. The dielectric constants measured using this fixed-frequency capacitance measurement system fall within the same general range as the values obtained using TDR equipment with the Topp or Roth general calibration equations, and they could probably be used directly in these equations after minor corrections. The conclusions drawn from these tests are that this measurement technique could and should be developed as an easier, more economical, and more easily automated and calibrated system for soil moisture measurement.

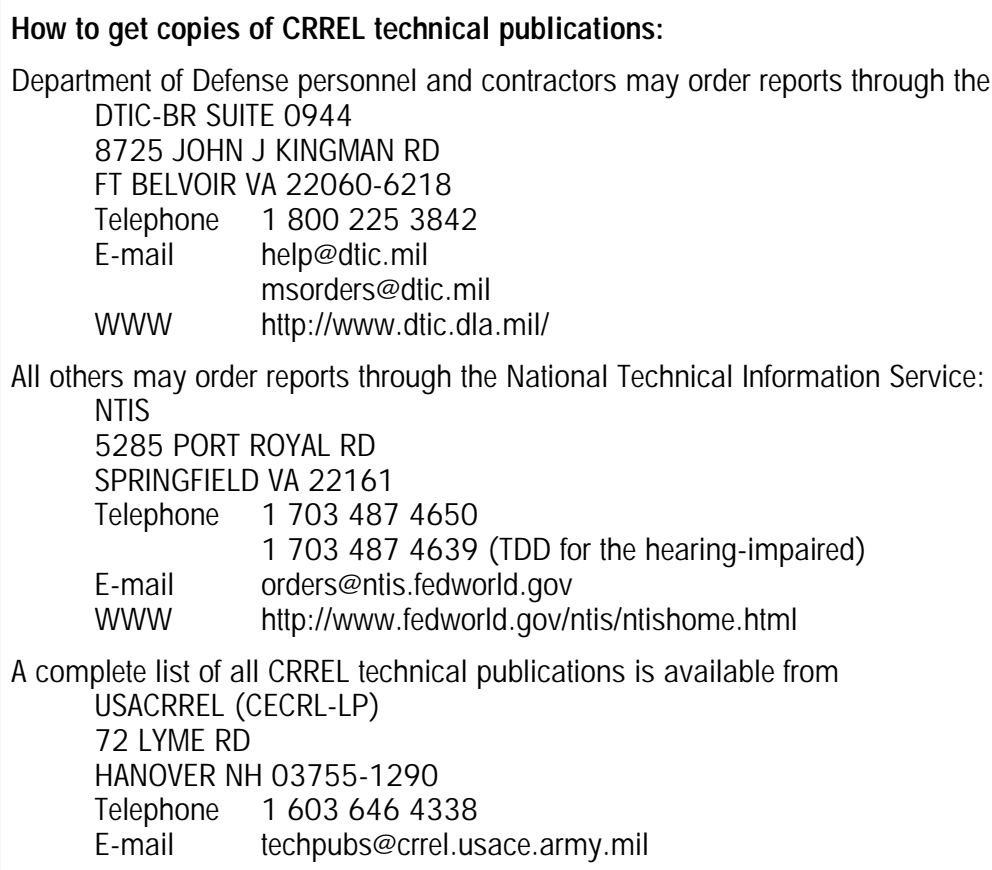

All others may order reports through the National Technical Information Service: NTIS

5285 PORT ROYAL RD

SPRINGFIELD VA 22161

Telephone 17034874650

17034874639 (TDD for the hearing-impaired)

E-mail orders@ntis.fedworld.gov

WWW http://www. fedworld.gov/ntis/ntishome.html

A complete list of all CRREL technical publications is available from

USACRREL (CECRL-LP)

72 LYME RD

HANOVER NH 03755-1290

Telephone 16036464338

E-mail techpubs@crrel.usace.army.mil

For information on all aspects of the Cold Regions Research and Engineering Laboratory, visit our World Wide Web site: http://www.crrel.usace.army.mil 


\section{Special Report 98-2}

\section{Soil Moisture Determinations Using Capacitance Probe Methodology}

Rona ld T. Atkins, Timothy Pangbum, Roy E. Bates, and Bruce E. Brockett 


\section{PREFACE}

This report was prepared by Ronald T. Atkins, Chief Engineer, Atkins Associates; Timothy Pangburn, Hydraulic Engineer, and Bruce E. Brockett, Physical Science Technician, Remote Sensing/GIS Center (RSGISC), U.S. Army Cold Regions Research and Engineering Laboratory (CRREL), Hanover, New Hampshire; and Roy E. Bates, Meteorologist, Vermont Weather Association, Ltd.

Funding for this work was provided by the Remote Sensing/Geographic Information Systems Center (RSGISC) under the direction of Dr. Harlan L. McKim.

The authors wish to acknowledge the assistance of Bryan Harrington in taking the field data, Allen Tice for his laboratory tests of the probes and test circuits, and James Morse for providing valuable advice as well as assistance in the preparation of the probes and test circuits.

The contents of this report are not to be used for advertising or promotional purposes. Citation of brand names does not constitute an official endorsement or approval of the use of such commercial products. 


\section{CONTENTS}

\begin{tabular}{|c|}
\hline troduction .............................. \\
\hline apacitance measurements ..... \\
\hline stem reliability and repeatability considerations \\
\hline electric constant measurements..... \\
\hline Using uninsulated probes .............. \\
\hline 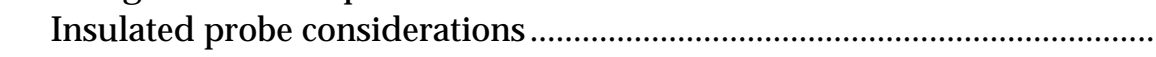 \\
\hline 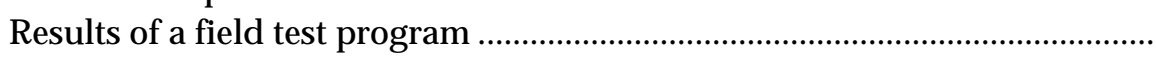 \\
\hline Test description ............................. \\
\hline Calibration ........... \\
\hline est results ........................... \\
\hline Conclusions and recommendations \\
\hline Literature cited \\
\hline Appendix A: Sample calculation ..................................... \\
\hline Appendix B: Raw data from probe tests \\
\hline 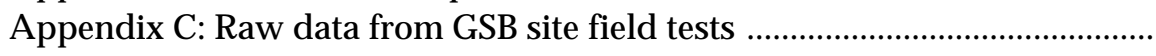 \\
\hline stract .................................. \\
\hline
\end{tabular}

\section{ILLUSTRATIONS}

Figure

1. Coaxial probe configuration .................................................................... 2

2. Simplified vector voltmeter and probe circuit........................................ 2

3. RC network circuits .........................................................................

4. GSB test site; 6-in. depth .................................................................. 13

5. GSB test site; 12-in. depth ...................................................................... 14

6. GSB test site; 18-in. depth .................................................................... 14

7. Moisture content vs. elapsed days; all three depths, GSB test site ....... 14

8. Percent moisture content by volume vs. dielectric constant ................. 19

\section{TABLES}

Table

1. Dielectric constant of water ....................................................................... 3

2. Statistical summaries ...............................................................................

3. Performance of insulated probes .............................................................

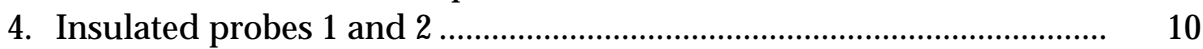

5. Correcting readings of insulated probes ................................................ 11 
Table Page

6. Equations used for calibration runs ......................................................... 12

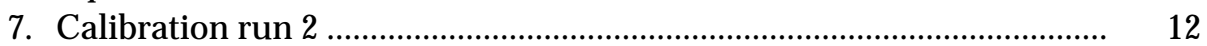

8. Calibration run 3 ............................................................................... 12

9. Percent dry weight .............................................................................. 13

10. Percent volume .................................................................................... 13

11. GSB test site, 6-in. depth ................................................................ 15

12. GSB test site, 12-in. depth ................................................................. 16

13. GSB test site, 18-in. depth ...................................................................... 17

14. Soil moisture calculations …………………......................................... 20 


\title{
Soil Moisture Determinations Using Capacitance Probe Methodology
}

\author{
RONALD T. ATKINS, TIMOTHY PANGBURN, \\ ROY E. BATES, AND BRUCE E. BROCKETT
}

\section{INTRODUCTION}

This report provides the initial test results of a method for determining soil moisture by the measurement of the related parameter of the dielectric constant of the soil. The concept of measuring soil moisture by measuring the capacitance or dielectric constant of the soil is not new; however, the emphasis on this technique has most recently been on the measurement of the dielectric constant using time domain reflectometry (TDR). The method described here measures the capacitance directly and was developed jointly by Dartmouth College and the U.S. Army Corps of Engineers, Civil Works Remote Sensing Research Program (CRREL). Thus, the method will be referred to as the Dartmouth/CRREL system throughout this report.

The objectives of the tests described here were to

1. Provide initial data that would demonstrate the proof of concept.

2. Provide initial data on the performance limits of the electrical measurement equipment.

3. Report the results of a field measurement program that used this technique to measure soil moisture throughout an entire winter freeze-thaw cycle.

This soil moisture measurement technique is based on the concept that the dielectric constant of a dry material consisting of soil particles and air is relatively small (1.5 to 4$)$, whereas the dielectric constant for water is very much larger (80 at room temperature). Therefore, even small amounts of water in a soil cause the dielectric constant of the resultant soil-water-air mixture to exhibit a composite dielectric constant that can be related to the soil moisture content through a simple calibration procedure. Moreover, this measurement may be accomplished with the use of electronic measurement equipment that is highly repeatable and that can therefore be expected to determine soil moisture reliably through the indirect measurement of the capacitance of a probe placed in the soil. Since the composite soilwater-air dielectric constant can be expected to exhibit typical Debye spread, the calibration should be accomplished at the same frequency at which soil moisture measurements are expected to be taken. For the tests described in this report, a $10-\mathrm{MHz}$ frequency was used. For more discussion on frequency effects, see Campbell (1988).

\section{CAPACITANCE MEASUREMENTS}

The capacitance probe and its accompanying readout system as described here were developed cooperatively by Dartmouth College and CRREL. The sensor itself is a coaxial probe containing five heavy steel tines mounted on the outer ring of a copper base as one plate of the capacitor and a central steel tine at the center of the probe assembly as the other (Fig. 1). The original design requirements were for a probe that would be strong enough to withstand repeated insertions and extractions from soils in a field measurement program and yet be sensitive enough to determine soil moisture to within 5\% by volume. The readout electronics were designed to measure the capacitance of the probe directly so that field measurements could be made using battery-operated equipment with data displayed directly on digital panel meters and so that the output could be interfaced to data logging equipment at a later date. 


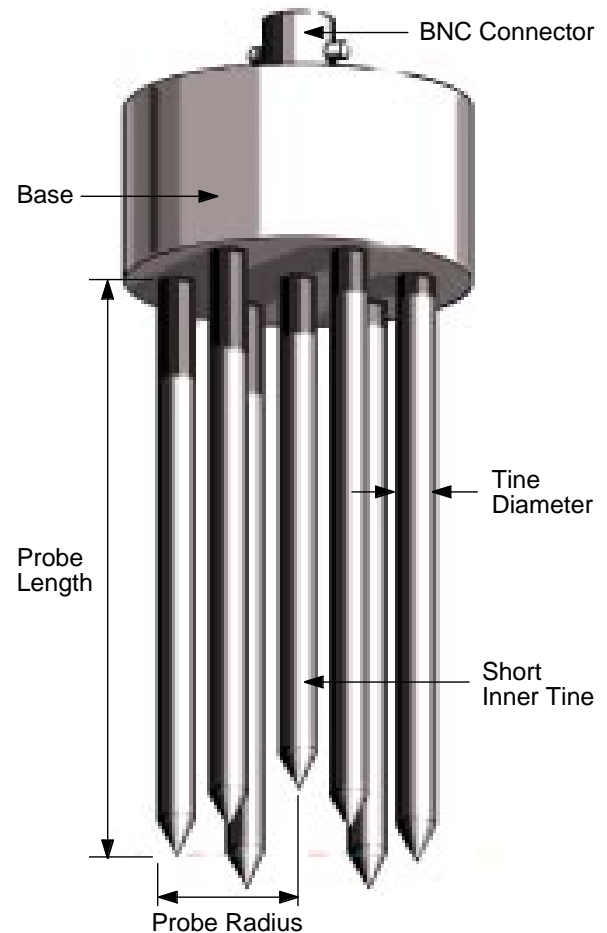

Figure 1. Coaxial probe configuration.

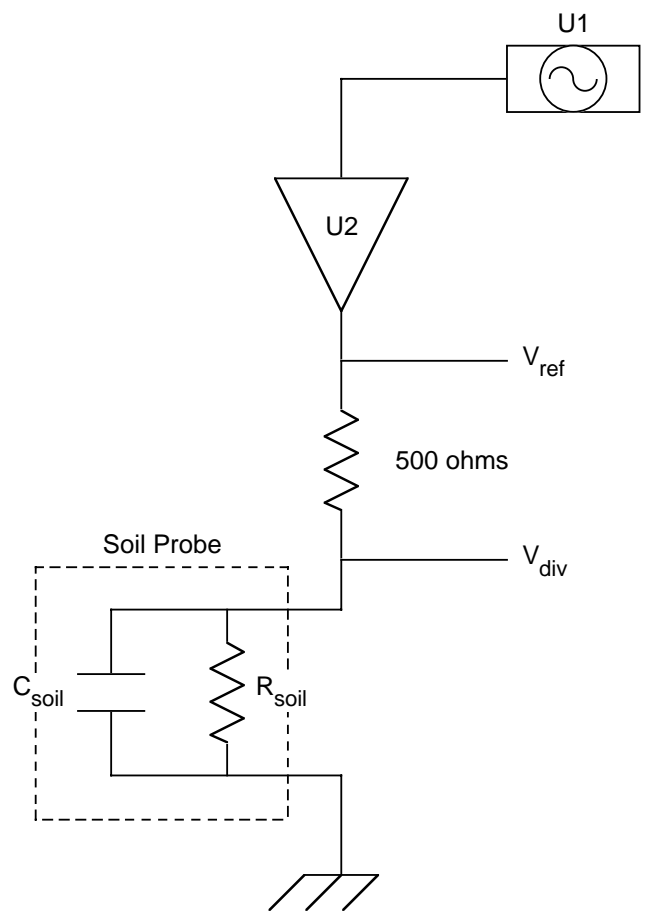

Figure 2. Simplified vector voltmeter and probe circuit.
A simplified circuit diagram of the measurement electronics is shown in Figure 2. As can be seen, three measurement voltages are required:

- The applied voltage, $V_{\text {ref }}$

- The voltage drop across the probe circuit, $V_{\text {div }}$

- The phase voltage between $V_{\text {ref }}$ and $V_{\text {div }}$, $V_{\mathrm{ph}}$.

In this simplified example, the capacitance of the probe is calculated using

$$
C=V_{\text {ref }} \times \sin V_{\mathrm{ph}} /\left(\mathrm{V}_{\mathrm{div}} \times \omega \times R\right)
$$

where $R=500 \mathrm{ohms}$ for this circuit $\omega=62.8 \times 10^{6} \mathrm{~Hz}$.

The total probe circuit actually consists of the probe capacitance in parallel with the capacitance of the coaxial cable that connects the probe to the readout box. To provide optimum sensitivity to the measurement of the capacitance of the soil, a variable inductance was placed in parallel with the probe cable input connector so that the capacitance of the cable itself could be nulled out of the measurement process. By using this variable inductor, the individual cable's capacitance may be eliminated from the measurement so that only the probe's capacitance is "seen" by the measurement electronics, thus simplifying the calculations required to determine the probe capacitance using $V_{\text {ref, }} V_{\text {div, }}$ and $V_{\mathrm{ph}}$. In addition, as long as a standard cable length is used for each field measurement, the process of nulling out the cable capacitance is required only once for each of the measurement circuits. Since the capacitance per unit length of coaxial cable is very uniform, the error caused by using different cables should be very small as long as the cables are all of the same length and have the same capacitance per unit length.

While the correction for various cable lengths may be reduced to a small error or actually measured and accounted for in the calculations, there are two problems with this method that need careful consideration and that can cause considerable errors if not accounted for.

First, the dielectric constant $K$ of a material is defined as the ratio of the permittivity of the medium $\varepsilon$ to the permittivity of free space (a vacuum or air as a very close approximation); $\varepsilon_{0}=8.85$ $\mathrm{pF} / \mathrm{m}$ in the MKS system, for instance: 


$$
\varepsilon=K \times \varepsilon_{0}
$$

where $\varepsilon_{0}=8.85 \mathrm{pF} / \mathrm{m}$.

Note that $K=1$ for air and for a vacuum.

Since capacitances are measured using this particular technique, the dielectric constant is the ratio of the capacitance of the soil divided by the capacitance of air (or of some other material whose dielectric constant is well known, such as water). Thus

$$
\begin{aligned}
C_{\text {soil }}= & K_{\text {soil }} \times \varepsilon_{0} \times(\text { a constant } \\
& \text { based on probe geometry })
\end{aligned}
$$

and

$$
\begin{aligned}
C_{\text {air }}= & K_{\text {air }} \times \varepsilon_{0} \times(\text { a constant based } \\
& \text { on probe geometry })
\end{aligned}
$$

so that

$$
K_{\text {soil }}=C_{\text {soil }} / C_{\text {air }} \text {, since } K_{\text {air }}=1 .
$$

Thus, the air capacitance for each probe must be found or else an average value for all probes must be established and the resultant error from using this average value determined. Another approach would be to use water rather than air as a reference material. For this approach, the temperature of the water should be determined and used, as shown in Table 1. Note that the capacitance of the probe in air can be found using water as a reference material by using the relationship

$$
C_{\text {air }}=C_{\text {water }} / K_{\text {water }} \text {. }
$$

Typically $K_{\text {water }}$ is 80 at room temperature, but the actual value for any temperature may be found in Table 1.

A second and much more serious error is the use of this measurement technique in a highly saline soil (desert salt flats or possibly under a

Table 1. Dielectric constant of water.

\begin{tabular}{cccc}
$\mathrm{T}\left({ }^{\circ} \mathrm{C}\right)$ & $\mathrm{K}$ & $\mathrm{T}\left({ }^{\circ} \mathrm{C}\right)$ & $\mathrm{K}$ \\
\hline 0 & 88.00 & 40 & 73.28 \\
5 & 86.40 & 45 & 71.59 \\
10 & 84.11 & 50 & 69.94 \\
15 & 82.22 & 60 & 66.74 \\
20 & 80.36 & 70 & 63.68 \\
25 & 78.54 & 80 & 60.78 \\
30 & 76.75 & 90 & 57.98 \\
35 & 75.00 & 100 & 55.33 \\
\hline
\end{tabular}

pavement where salt is used in the snow-removal program). Since salt water is so highly conductive, the presence of salt in any appreciable amount causes the probe to read just the resistance of the soil, or worse, the inductance of the nulling inductor, since the capacitance of the probe is shorted out by the low resistance of the salt water. The extent of this problem can be demonstrated by such a simple procedure as placing the probe in water, observing the values of $V_{\text {ref }}, V_{\text {div }}$, and $V_{\mathrm{ph}}$, and then adding salt to the water to lower the conductivity of the solution and observing the changes in $V_{\text {ref }}, V_{\mathrm{div}}$, and $V_{\mathrm{ph}}$. If these altered readings are used to carry out an actual calculation for capacitance, it will be seen that when the salt is added (simulating an electrical short circuit), $V_{\mathrm{ph}}$ goes positive, indicating an inductance rather than a capacitance. If the dielectric constant were to be calculated for these values, it would be negative (which is, of course, impossible).

The extent to which each of these two problems affects the use of this technique for the measurement of soil moisture is discussed in some detail in this report.

Another concern, not necessarily a problem, is the conversion of a dielectric constant measurement to a soil moisture measurement. The simplest and most direct method is to measure the dielectric constant at known values of soil moisture as determined by actually weighing the test soil sample. Starting with a totally dry soil and adding known amounts of water generates a curve of dielectric constant vs. moisture content (percent of dry weight) that will serve as a calibration curve for all similar type soils. Such a procedure will not account for the variability of soil types, so a new curve would have to be generated for each new soil type; even then there is substantial variability within a given soil type since soils are nonhomogeneous. The amount of the error within any soil type can be established using statistical methods, but the process requires enough data to be able to make statistically valid statements. An alternative approach would be to determine the dielectric constant as a function of the volumetric moisture content. These data may then be used to determine the moisture content for soils with different densities. Such a procedure requires additional testing to determine the dry density and the specific gravity of the particular soil under consideration.

Several researchers have used calibration methods such as these to generate equations that relate 
the dielectric constant to volumetric moisture content using time domain reflectometry (TDR) techniques to measure the dielectric constant. Among the first researchers to do this were Topp et al. (1980), whose curve is a third-order polynomial that matches the calibration curve quite closely and has been used by other researchers as a "universal" calibration equation for volumetric moisture contents. Another group of researchers, Roth et al. (1990), generated a much more elaborate equation that is based on dielectric mixing theory and that requires a knowledge of the dielectric constant of the dry soil as well as its porosity. It should be noted that the use of these equations requires independent calibrations to establish the error limits for any particular soil.

Topp et al.'s equation (based on an empirical fit of available calibration data):

$$
\begin{aligned}
\theta= & \left(-5.3 \times 10^{-2}\right)+\left(2.93 \times 10^{-2}\right) \times \varepsilon \\
& -\left(5.5 \times 10^{-4}\right) \times \varepsilon^{2}+\left(4.3 \times 10^{-4}\right) \times \varepsilon^{3}
\end{aligned}
$$

where $\theta=$ volumetric water content.

Roth et al.'s equation (based on dielectric mixing theory):

$$
\varepsilon_{\mathrm{c}}=\left[\theta \times \varepsilon_{\mathrm{w}}^{\alpha}+(1-\eta) \times \varepsilon_{\mathrm{s}}^{\alpha}+(\eta-\theta) \times \varepsilon_{\mathrm{a}}^{\alpha}\right]^{1 / \alpha}
$$

where $\varepsilon_{\mathrm{c}}=$ composite dielectric constant

$\theta=$ volumetric water content

$\varepsilon_{\mathrm{w}}=$ dielectric constant of water

$\varepsilon_{\mathrm{s}}=$ dielectric constant of the soil

$\varepsilon_{\mathrm{a}}=$ dielectric constant of air

$\eta=$ the soil's porosity

$\alpha=0.46$.

The alpha term $(\alpha)$ is required by dielectric mixing theory and accounts for the molecular orientation of the three materials in this system, namely air, soil, and water. For a soil-air-water mixture, the authors determined that the best fit was obtained between gravimetrically determined soil moisture data and this equation when $\alpha=0.46$.

It is also possible to calibrate this soil moisture measurement technique directly for volumetric moisture content. For example, the probe might be placed directly in a test apparatus with a known volume of soil and then known volumes of water added to provide calibration data. Such a procedure could then be used to determine how well equations such as Topp and his colleagues' would apply when the dielectric constant is measured at $10 \mathrm{MHz}$ using capacitance measurements rather than the TDR measurements used by Topp and his co-workers.

Since there are obvious problems associated with this method for determining soil moisture, it seems appropriate to justify the effort being expended to develop it:

1. The ideal soil moisture measurement system would have the following characteristics:

- Accuracy

- Good long-term stability

- Reliability

- Easily read using untrained observers

- Low cost

- Easily adapted to dataloggers

- Easily calibrated

- Easily installed

- Ruggedness

- Resistance to environmental parameters such as temperature and humidity.

2. A detailed, serious review of the soil moisture literature will reveal that there is no presently available method that can be considered to meet the ideal characteristics (Campbell 1988). In fact, most methods have serious failings in several of these areas.

3 . It is believed that the capacitance measurement system described here (or one very similar to it) can and will ultimately meet the requirements for an ideal system.

\section{SYSTEM RELIABILITY AND REPEATABILITY CONSIDERATIONS}

As part of the initial testing program for this soil moisture measurement system, the performance limits of the electronics were established. The objective of these initial tests was to establish the accuracy, reliability, and repeatability of the electronic circuits as a separate portion of the total soil moisture measurement procedure.

To determine how well the electronic circuits performed, three test circuits consisting of resistance-capacitance (RC) networks were fabricated. A series of tests were performed at different times: once in the spring of 1991 and again in the fall of 1991. The circuits for each test sequence are shown in Figure 3. The tests were conducted at two different times, with the data taken by two different observers in order to provide some randomness to the measurement process. Note that these tests were conducted with the following electronic measurement equipment: 
- Measurement electronics consisting of two separate circuits but installed in a single chassis (box). Three such boxes were tested, with each box containing two separate measuring circuits. For ease of identification, the boxes were simply called box 2 , box 3 , and box 4 . For each box, the two separate measurement circuits are called probe 1 circuit and probe circuit 2.

- Test circuits as shown in Figure 3 are identified by their actual capacitance value (152.3 $\mathrm{pF}$, for example). One box (box 3) was left unnulled in the second set of tests just to provide some comparison to the nulled cable measurements.

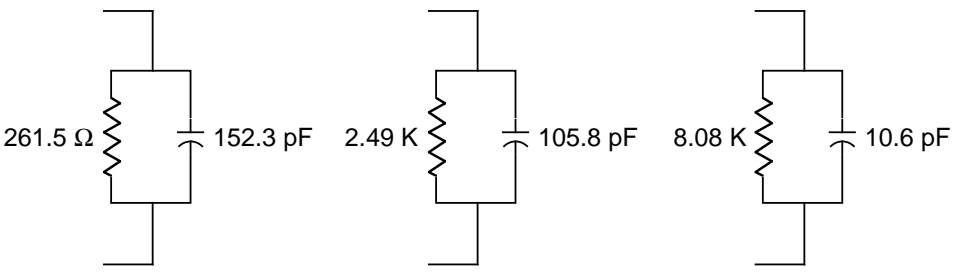

The initial measurement procedure consisted of nulling the cable capacitance of the test boxes and then connecting each of the test RC networks to each measurement circuit (probe 1 and probe 2), with readings of $\mathrm{V}_{\text {ref }}, \mathrm{V}_{\mathrm{div}}$, and $\mathrm{V}_{\mathrm{ph}}$

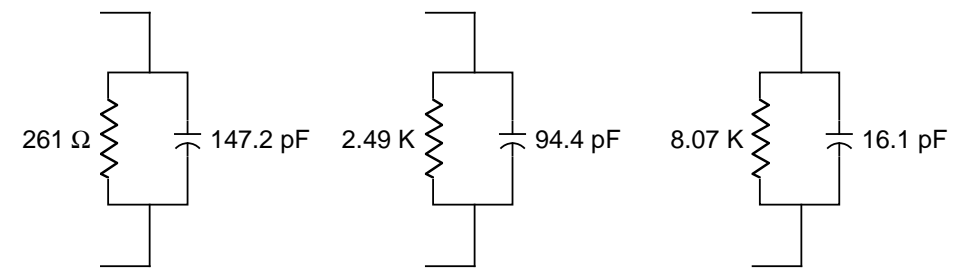

Figure 3. Resistance-capacitance ( $R C$ ) network circuits.

Table 2a. Statistical summaries: Preliminary tests (spring 1991).

\begin{tabular}{|c|c|c|}
\hline Box 2 & Both probe circuits nulled & \\
\hline & & $\underline{152.3 \mathrm{pF} \text { circuit }}$ \\
\hline & $n=8 \bar{C}=157.0 \mathrm{pF}$ & $s=8.5$ \\
\hline & $\%$ standard deviation $=5.4$ & \\
\hline & $\%$ error $=3.0$ & \\
\hline & & $10.6 \mathrm{pF}$ circuit \\
\hline & $n=8 \bar{C}=14.8 \mathrm{pF}$ & $s=2.2$ \\
\hline & $\%$ standard deviation $=14.8$ & \\
\hline & $\%$ error $=39.6$ & \\
\hline & & $\underline{105.8 \mathrm{pF} \text { circuit }}$ \\
\hline & $n=8 \bar{C}=127.0 \mathrm{pF}$ & $s=0.41$ \\
\hline & $\%$ standard deviation $=0.3$ & \\
\hline & $\%$ error $=20.0$ & \\
\hline Box 3 & Both probe circuits nulled & \\
\hline & & $\underline{152.3 \mathrm{pF} \text { circuit }}$ \\
\hline & $n=7 \bar{C}=208.2 \mathrm{pF}$ & $s=5.2$ \\
\hline & $\%$ standard deviation $=2.5$ & \\
\hline & $\%$ error $=36.7$ & \\
\hline & & $10.6 \mathrm{pF}$ circuit \\
\hline & $n=7 \bar{C}=16.3 \mathrm{pF}$ & $s=0.72$ \\
\hline & $\%$ standard deviation $=4.4$ & \\
\hline & $\%$ error $=53.8$ & \\
\hline & & $105.8 \mathrm{pF}$ circuit \\
\hline & $n=7 \bar{C}=3.17 \mathrm{pF}$ & $s=0.41$ \\
\hline & $\%$ standard deviation $=2.4$ & \\
\hline & $\%$ error $=25.6$ & \\
\hline
\end{tabular}


Table 2a (cont'd). Statistical summaries: Preliminary tests (spring 1991)

\begin{tabular}{|c|c|c|}
\hline Box 4 & Both probe circuits nulled & \\
\hline & & $\underline{152.3 \mathrm{pF} \text { circuit }}$ \\
\hline & $n=7 \bar{C}=154.0 \mathrm{pF}$ & $s=0.54$ \\
\hline & $\%$ standard deviation $=0.3$ & \\
\hline & $\%$ error $=1.1$ & \\
\hline & & $10.6 \mathrm{pF}$ circuit \\
\hline & $n=7 \bar{C}=15.9 \mathrm{pF}$ & $s=0.6$ \\
\hline & $\%$ standard deviation $=-3.8$ & \\
\hline & $\%$ error $=-50.0$ & \\
\hline & & $\underline{105.8 \mathrm{pF} \text { circuit }}$ \\
\hline & $n=8 \bar{C}=118.6 \mathrm{pF}$ & $s=0.3$ \\
\hline & $\%$ standard deviation $=0.3$ & \\
\hline & $\%$ error $=-12.1$ & \\
\hline & Overall: Standard deviation: & $\Sigma=34.2 \quad n=9$ \\
\hline & & Average: $3.8 \%$ \\
\hline & \% errors: & $\Sigma=241.9 \quad n=9$ \\
\hline & & Average: $-26.9 \%$ \\
\hline Box 2 and 4 & Both probe circuits nulled & \\
\hline & & $\underline{147.2 \mathrm{pF} \text { circuit }}$ \\
\hline & $n=12 \bar{C}=163.5 \mathrm{pF}$ & $s=4.4$ \\
\hline & $\%$ standard deviation $=2.7$ & \\
\hline & $\%$ error $=11.1$ & \\
\hline & & $\underline{94.4 \mathrm{pF} \text { circuit }}$ \\
\hline & $n=12 \bar{C}=121.6 \mathrm{pF}$ & $s=0.59$ \\
\hline & $\%$ standard deviation $=4.8$ & \\
\hline & $\%$ error $=28.8$ & \\
\hline & & $\underline{16.1 \mathrm{pF} \text { circuit }}$ \\
\hline & $n=12 \bar{C}=26.1 \mathrm{pF}$ & $s=1.2$ \\
\hline & $\%$ standard deviation $=4.6$ & \\
\hline & $\%$ error $=-62.1$ & \\
\hline & Overall: Standard deviation: & $\Sigma=12.1 \quad n=3$ \\
\hline & & Average: $4.0 \%$ \\
\hline & \% errors: & $\Sigma=102.0 \quad n=3$ \\
\hline & & Average: $-34.0 \%$ \\
\hline Bo 3 & Both probe circuits not nulled & \\
\hline & & $\underline{147.2 \mathrm{pF} \text { circuit }}$ \\
\hline & $n=8 \bar{C}=206.3 \mathrm{pF}$ & $s=3.8$ \\
\hline & $\%$ standard deviation $=1.8$ & \\
\hline & $\%$ error $=-40.1$ & \\
\hline & & $\underline{94.4 \mathrm{pF} \text { circuit }}$ \\
\hline & $n=8 \bar{C}=130.7 \mathrm{pF}$ & $s=1.01$ \\
\hline & $\%$ standard deviation $=0.80$ & \\
\hline & $\%$ error $=-38.4 \%$ & \\
\hline & & $16.1 \mathrm{pF}$ circuit \\
\hline & $n=8 \bar{C}=27.1 \mathrm{pF}$ & $s=0.43$ \\
\hline & $\%$ standard deviation $=1.5$ & \\
\hline & $\%$ error $=-68.3$ & \\
\hline & Overall: Standard deviation: & $\Sigma=4.1 \quad n=3$ \\
\hline & & Average: $1.4 \%$ \\
\hline & $\%$ errors: & $\Sigma=146.8 \quad n=3$ \\
\hline & & Average: $-48.9 \%$ \\
\hline
\end{tabular}


Table 2b. Statistical summaries: All RC network tests, spring and autumn data, both probe circuits for each box.

\begin{tabular}{cccc} 
Box & Percent error & $\begin{array}{c}\text { Standard deviation as } \\
\text { a percent of the mean }\end{array}$ & Nulled? \\
\hline 2 & -3.0 & 5.4 & Yes \\
2 & -39.6 & 14.8 (outlier ?) & Yes \\
2 & -20.0 & 0.3 & Yes \\
3 & -36.7 & 2.5 & Yes \\
3 & -53.8 & 4.4 & Yes \\
3 & -25.6 & 2.4 & Yes \\
4 & -1.1 & 0.3 & Yes \\
4 & -50.0 & 3.8 & Yes \\
4 & -12.1 & 0.3 & Yes \\
$2 \& 4$ & -11.1 & 2.7 & Yes \\
$2 \& 4$ & -28.8 & 4.8 & Yes \\
$2 \& 4$ & -62.1 & 4.6 & Yes \\
3 & -40.1 & 1.8 & No \\
3 & -38.4 & 0.8 & No \\
3 & -68.3 & 1.5 & No \\
\hline
\end{tabular}

Average error of all nulled circuits: $-28.6 \%$

Average error of all unnulled circuits: $-48.9 \%$

Average standard deviations as a percent of the mean:

all nulled circuits: $2.9 \%$

all unnulled circuits: $1.3 \%$

An examination of these data shows that while the electronic circuits themselves are not very accurate for the measurement of capacitance, they are nevertheless highly repeatable and reliable. This conclusion indicates that the circuits will work very well for soil moisture measurements once a calibration has been performed. Another tentative conclusion that might be drawn from the statistical data is that the best accuracy is achieved when the cable's capacitance is nulled (note that the tabulated summaries include all the unnulled portion so that the actual sample population for the unnulled tests is 24 points, not the three values listed in Table $2 b$ ). Better accuracy might be expected from a nulled circuit since the correction for cable capacitance in the unnulled circuit can be as large as the measured value itself. However, note also that there is apparently no significantly valid reason to assume that the unnulled test data is less repeatable than the nulled circuit data.

\section{DIELECTRIC CONSTANT MEASUREMENTS}

\section{Using uninsulated probes}

After the initial all-electronic measurements were completed, a series of tests was conducted to determine how well the technique described in the Capacitance Measurements section above would measure the dielectric constant of a known liquid. This set of tests required the addition of the probes to the test system; it demonstrates the use of a statistical approach for this method for converting the capacitance as measured by the system to a dielectric constant measurement. (Previous reports describing the use of this measurement technique reported capacitance as the output data but never reported dielectric constants or suggested a method for converting the capacitance measurements to a dielectric constant.) In addition, as part of the test procedure, the center tine of two of the test probes was covered with heat-shrink tubing to eliminate ionic conduction between the capacitor's plates. This modification to the otherwise bare tines was a test program to determine if the salinity problem (see the discussion on page 3) could be solved. The concept was to prevent highly conductive saline soils from shorting out the capacitance measurement. The error in the capacitance measurement could then be corrected as a part of the calibration process.

It should be noted that the probes initially supplied for these tests had BNC connectors mounted directly in their base so the connecting cable was attached at that point. These probes were designed to be inserted into the soil for a surface measurement, so the BNC cable connection was perfectly adequate. However, the BNC connector was not watertight, so for probes that were to be buried and left in the soil for an extended period it became necessary to replace the BNC connectors with a permanent, sealed, waterproof connection between the probe and cable. The sealing compound used for this probe modification was a two-part encapsulating epoxy. The requirement to follow this procedure further complicated the measurement process since it dedicated each probe to a given cable length and also introduced an additional dielectric constant, that of the epoxy into the measurement probe circuit.

The method for converting a capacitance measurement to a dielectric constant as described in the Capacitance Measurements section is summarized below:

1. Determine the capacitance of the probe in air (eq 1 and 3).

2. Take the soil measurement and calculate the capacitance (eq 1).

3. Divide the soil capacitance by the air capacitance; the resultant quotient is the dielectric constant of the soil (eq 2).

Note that the air capacitance is most easily mea- 
sured using water as the reference material and then finding $C_{\text {air }}$ as the capacitance of the water, $C_{\text {water }}$ divided by the dielectric constant of the water, $K_{\text {water, }}$ at the measurement temperature. Note also that the best accuracy would be expected when the cable has been nulled.

Using the above measurement sequence, a set of 23 test probes was fabricated and used to measure the dielectric constant of methanol $(K=32.65)$. A data set was taken for both probe circuits in boxes 2, 3, and 4, leaving box 3 unnulled. Probes $M$ and $U$ were insulated. Observations with each probe were made in distilled water and in methanol. The raw data and the capacitance and dielectric constant calculations are shown in Appendix B. A sample calculation is given below:

Box 2: Average capacitance for the distilled water $\left(C_{\text {water }}\right)$ is $249.6 \mathrm{pF}$; the dielectric constant for water at $21.6^{\circ} \mathrm{C}$ is 79.78 :

$$
C_{\text {air }}=249.6 / 79.78=3.1 \mathrm{pF} \text {. }
$$

For probe A in methanol, $C=94.0 \mathrm{pF}$, so

$$
\begin{aligned}
K_{\text {methanol }}= & 94.0 / 3.1=30.3 \text { as measured by } \\
& \text { probe } \mathrm{A} .
\end{aligned}
$$

The following is a statistical summary of the entire test sequence:

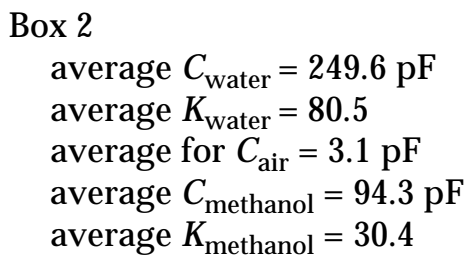

Box 4

$$
\begin{aligned}
& \text { average } C_{\text {water }}=238.3 \mathrm{pF} \\
& \text { average } K_{\text {water }}=81.6 \\
& \text { average for } C_{\text {air }}=2.9 \mathrm{pF} \\
& \text { average } C_{\text {methanol }}=86.3 \mathrm{pF} \\
& \text { average } K_{\text {methanol }}=29.5
\end{aligned}
$$

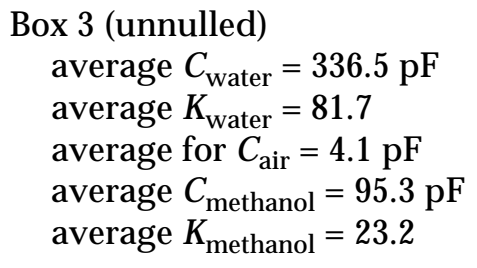

Analysis of this data indicates that apparently the cable correction for the distilled water measurements for box 3 (unnulled) was too small, $336.5 \mathrm{pF}$ after cable correction, as compared with
249.6 and $238.3 \mathrm{pF}$ for the nulled cable circuits. This overestimated capacitance for the distilled water led to a high $C_{\text {air }}$, which in turn caused the calculated values for $K_{\text {methanol }}$ to be too low. The conclusion is that the cable should be nulled to obtain best accuracy in the dielectric constant measurements.

\section{Insulated probe considerations}

The measurement process described above may also be used for insulated tines. For example, the probes may be calibrated and used in the same way as the uninsulated probes, or the water measurements may be used to determine a series capacitance that may then be used to correct the insulated probe readings so that they agree with the uninsulated probes. Both procedures are discussed here. It should be noted that for insulated tines the resolution of the measurement process is reduced. Nevertheless, an insulated probe may be the only solution for a moisture content measurement in a highly saline soil, and while the resolution of the measurement may be reduced, the accuracy may still be acceptable.

To document the requirement to insulate at least one probe in order to make meaningful measurements in a saline soil, a set of test probes was fabricated using two types of insulating materials: a clear polyolefin heat-shrink tubing and a two-part epoxy resin. The following is the pertinent electrical data for each material:

Polyolefin Dielectric constant at 1 MHz: 2.5

Volume resistivity: $10^{15} \Omega \cdot \mathrm{cm}$

Epoxy resin Dielectric constant at $100 \mathrm{kHz}$ : 3.8 typical

Dielectric constant at $1 \mathrm{kHz}$ : 4.1 typical Volume resistivity: $4.2 \times 10^{16} \Omega \cdot \mathrm{cm}$ Dissipation factor at $100 \mathrm{kHz}: 0.01$

Dissipation factor at $1 \mathrm{kHz}: 0.01$

Other insulating materials with higher and lower dielectric constants and dissipation factors are commercially available. The above materials were used because they were on hand, not because they were the optimum materials for this particular application.

The typical performance of probes insulated with the polyolefin and the epoxy are shown in Table 3, which shows the requirement for insulating the probe to make even modestly accurate measurements in saline soils. This requirement 
Table 3. Performance of insulated probes.

Initial tests, 26 September 1990. No attempt was made to quantify the actual amount of salt (sodium chloride) added; these tests were run merely to demonstrate that uninsulated probes would not perform well in saline solutions and that insulated probes held some possibilities in this area. Tabular values are the calculated dielectric constant for the tap water used in these tests. The insulation on the test probe was a polyolefin heat-shrink tubing.

\begin{tabular}{lcccc} 
& $\begin{array}{c}\text { Distilled } \\
\text { water }\end{array}$ & $\begin{array}{c}\text { Salt } \\
\text { added }\end{array}$ & $\begin{array}{c}\text { More salt } \\
\text { added }\end{array}$ & $\begin{array}{c}\text { More salt } \\
\text { added }\end{array}$ \\
\hline $\begin{array}{l}\text { Uninsulated } \\
\text { Insulated }\end{array}$ & 65.9 & 36.2 & -18.7 & -42.0 \\
\hline
\end{tabular}

Detailed tests, 16 October 1991. Epoxy resin and heat-shrink tubing used as insulations. All readings were taken with box 2, probe circuit 1 .

Probes $\mathrm{M}$ and $\mathrm{U}$-epoxy insulation

Probes $\mathrm{F}$ and $\mathrm{H}$ - uninsulated

Probe T-insulated with heat-shrink tubing

\begin{tabular}{ccccccc} 
Probe & $\begin{array}{c}\text { Distilled } \\
\text { water }\end{array}$ & $0.001 \mathrm{~N}$ & $0.005 \mathrm{~N}$ & $0.01 \mathrm{~N}$ & $0.06 \mathrm{~N}$ & $0.1 \mathrm{~N}$ \\
\hline $\mathrm{M}$ & 80.0 & 79.8 & 90.5 & 117.2 & 210.0 & 220.1 \\
$\mathrm{U}$ & 79.1 & 77.9 & 89.8 & 118.2 & 202.4 & 210.4 \\
$\mathrm{~F}$ & 80.0 & 69.2 & 3.9 & -40.1 & -115.6 & -122.8 \\
$\mathrm{H}$ & 80.0 & 70.1 & 4.4 & -39.7 & -115.6 & -122.8 \\
$\mathrm{~T}$ & 80.0 & $\mathrm{ND}$ & $\mathrm{ND}$ & 97.1 & $\mathrm{ND}$ & 102.6 \\
\hline
\end{tabular}

Notes:

The dielectric constant was calculated by finding $C_{\text {air }}$ for the distilled water and then using this value to calculate the dielectric constants for the other molarities. Potassium chloride was the salt used for these tests. Tabular values are dielectric constants.

The uninsulated probes are essentially useless once the molarity is over $0.001 \mathrm{~N}$.

The epoxy probes have an excessive error above $0.005 \mathrm{~N}$.

The heat-shrink tubing is probably usable with acceptable error limits up to about $0.01 \mathrm{~N}$.

$\mathrm{ND}=$ no data taken at that molarity.

may be met using either of two methods for calibrating an insulated probe:

1. Calibrate the insulated probe using water as a reference material and apply the exact same procedure as is used for an uninsulated probe, or

2. Calculate an equivalent capacitance for the insulation and use it as a series capacitance to correct the insulated probe readings to indicate the same capacitance as an uninsulated probe.

Using procedure 1, the calculated values for methanol are shown in Table 4. The results of this method for calculating the dielectric constant of a known material are summarized here:
Box 2: Average $K=41.2$

Box 3: Average $K=43.3$

Box 4: Average $K=41.6$.

Since the methanol has an actual value of 32.65, the results of this particular method indicate a rather poor accuracy for dielectric constant calculations.

Applying procedure 2, the calculated values for methanol are shown in Table 5. The results of this method for calculating the dielectric constant are summarized below:

Box 2: Average $K=29.3$

Box 3: Average $K=31.2$

Box 4: Average $K=28.1$ 
Table 4. Insulated probes 1 and $2 . K_{\mathrm{w}}=79.78$.

\begin{tabular}{|c|c|c|c|c|c|c|c|c|c|c|c|}
\hline \multirow{2}{*}{ Probe } & & \multicolumn{5}{|c|}{ Distilled water } & \multicolumn{5}{|c|}{ Methanol } \\
\hline & & $\mathrm{V}_{\text {ref }}$ & $\mathrm{V}_{\text {div }}$ & $\mathrm{V}_{p h}$ & $\mathrm{C}$ & $C-C_{D}$ & $\mathrm{~V}_{r e f}$ & $\mathrm{~V}_{\text {div }}$ & $\mathrm{V}_{p h}$ & C & $C-C_{D}$ \\
\hline \multicolumn{12}{|c|}{ Box 2} \\
\hline & $\mathrm{M}$ & 0.954 & 0.205 & -71.3 & 140.3 & 141.3 & 0.971 & 0.371 & -58.0 & 70.6 & 71.5 \\
\hline & $\mathrm{U}$ & 0.958 & 0.212 & -71.4 & 136.3 & 137.3 & 0.971 & 0.372 & -58.0 & 70.4 & 71.3 \\
\hline & $\mathrm{M}$ & 0.956 & 0.210 & -71.3 & 137.2 & 138.2 & 0.971 & 0.377 & -57.8 & 69.3 & 70.3 \\
\hline & $\mathrm{U}$ & 0.959 & 0.217 & -71.3 & 133.2 & 134.2 & 0.971 & 0.378 & -57.8 & 69.2 & 70.1 \\
\hline \multicolumn{12}{|c|}{ Box 3} \\
\hline & M & 0.984 & 0.169 & -72.6 & 176.8 & 165.1 & 0.992 & 0.287 & -64.7 & 99.5 & 87.7 \\
\hline & $\mathrm{U}$ & 0.981 & 0.173 & -72.1 & 171.7 & 160.0 & 0.992 & 0.287 & -64.8 & 99.5 & 87.8 \\
\hline & $\mathrm{M}$ & 0.985 & 0.172 & -72.6 & 173.9 & 162.2 & 0.992 & 0.289 & -64.9 & 98.9 & 87.2 \\
\hline & $\mathrm{U}$ & 0.982 & 0.177 & -72.2 & 168.1 & 156.4 & 0.992 & 0.290 & -64.9 & 98.6 & 86.8 \\
\hline \multicolumn{12}{|c|}{ Box 4} \\
\hline & M & 0.992 & 0.233 & -71.7 & 128.7 & 129.7 & 0.992 & 0.425 & -59.3 & 63.9 & 64.9 \\
\hline & $\mathrm{U}$ & 0.993 & 0.242 & -71.5 & 123.8 & 124.9 & 0.990 & 0.426 & -58.6 & 63.1 & 64.2 \\
\hline & $\mathrm{M}$ & 0.993 & 0.257 & -71.1 & 116.3 & 117.4 & 0.992 & 0.426 & -59.7 & 64.0 & 65.0 \\
\hline & $\mathrm{U}$ & 0.993 & 0.244 & -71.0 & 122.5 & 123.5 & 0.991 & 0.426 & -58.5 & 63.1 & 64.2 \\
\hline
\end{tabular}

$\begin{array}{ll}\text { Box } 2 & C_{D}=-1.59 \mathrm{pF} / 1.78=-0.89 \mathrm{pF} \text { offset } \\ \text { Box } 3 & C_{D}=26.9 \mathrm{pF} / 2.28=11.76 \mathrm{pF} \text { offset } \\ \text { Box } 4 & C_{D}=-2.0 \mathrm{pF} / 1.85=-1.06 \mathrm{pF} \text { offset }\end{array}$

Ratio of distilled-water dummy readings and insulated and uninsulated $C$ readings in distilled water:
Box 2 average distilled water capacitance $=137.7 \mathrm{pF}$ $C_{\text {air }}=137.7 / 79.78=1.72 \mathrm{pF}$ average methanol capacitance $=70.8 \mathrm{pF}$ dielectric constant $K=70.8 / 1.72=41.2$
Box 3 average distilled water capacitance $=160.9 \mathrm{pF}$ $C_{\text {air }}=160.9 / 79.78=2.01 \mathrm{pF}$ average methanol capacitance $=87.4 \mathrm{pF}$ dielectric constant $K=87.4 / 2.01=43.5$
Box 4 average distilled water capacitance $=123.9 \mathrm{pF}$ $C_{\text {air }}=123.9 / 79.78=1.55 \mathrm{pF}$ average methanol capacitance $=64.6 \mathrm{pF}$ dielectric constant $K=64.6 / 1.55=41.7$

Based purely on the results of these two methods for calculating the dielectric constant of a material, procedure 2 would seem to offer much more accurate data.

\section{RESULTS OF A FIELD TEST PROGRAM}

During the winter of 1990-1991, a field test program was conducted to demonstrate and gain experience in the use of this method for making actual soil moisture measurements.

\section{Test description}

For this field demonstration, a test pit (called the GSB test site) was dug in a test area located next to the FERF building at USACRREL in Hanover, New Hampshire. Three insulated probes were inserted into the wall of the test pit at depths of 6,12 , and 18 in. $(15.25,30.5$, and $45.75 \mathrm{~cm})$. Thermocouples were mounted on the probes so that temperature at each depth could also be recorded as part of the measurement program. Thirty-inch cables were attached to the probes using a two-part epoxy resin to ensure the watertight integrity of the connection. Data were read manually throughout the winter's freeze-thaw cycle at all three depths. Box 3 (nulled) was the readout instrument. Soil temperatures were read with a handheld thermocouple reader.

Data taking started on 19 November 1990 and continued until 3 June 1991. A complete copy of the raw data, the dielectric constants calculated 
Table 5. Correcting readings of insulated probes to read the same as the uninsulated readings. (The test material is methanol.)

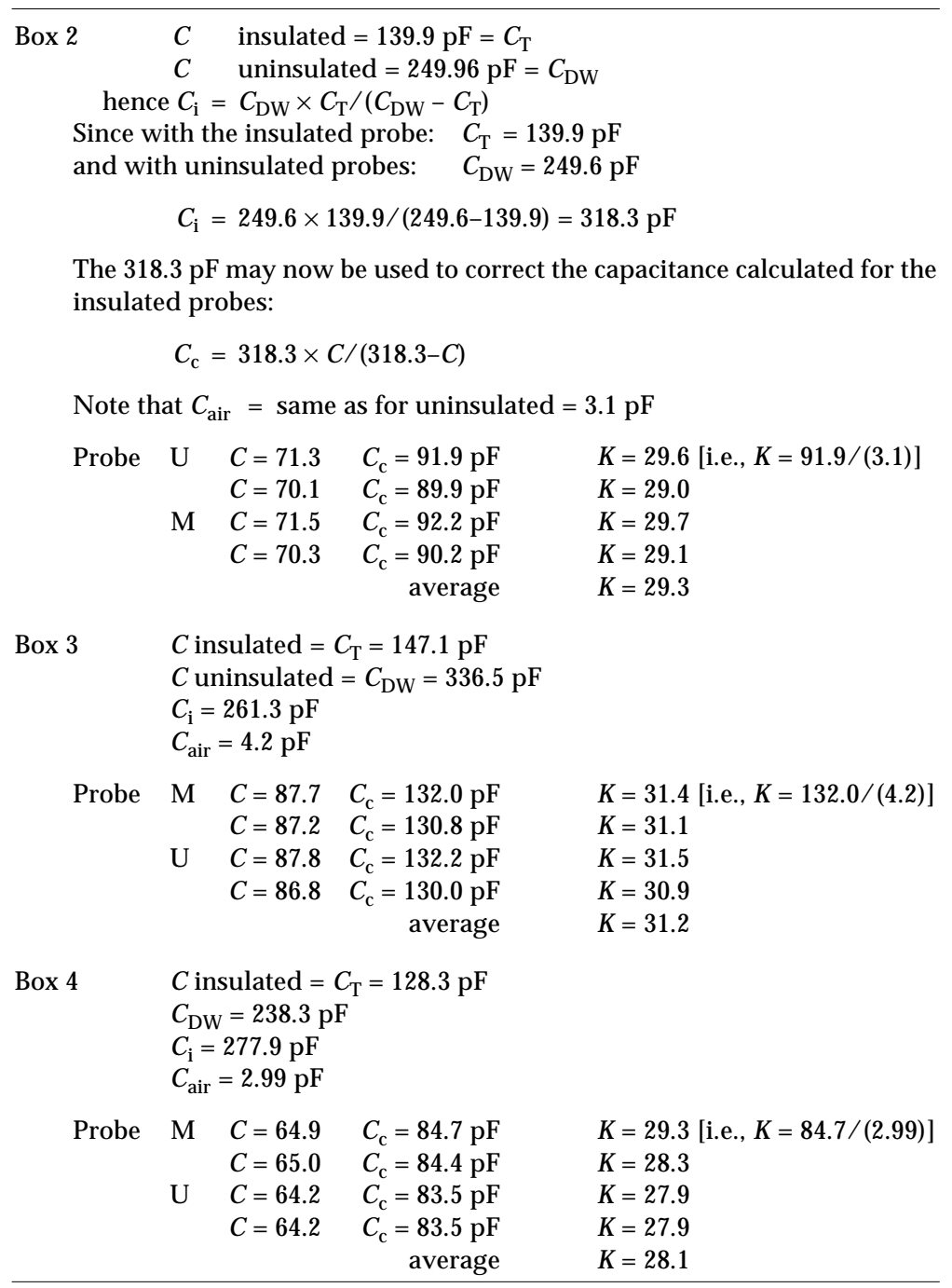

from this data, and the temperatures at each probe depth are shown in Appendix C. The depths for the probes, identified in Appendix C as F47, F01, and F42, are as follows:

Probe F47-6 in. $(15.25 \mathrm{~cm})$ below the surface Probe F01-12 in. $(30.5 \mathrm{~cm})$ below the surface Probe F42-18 in. $(45.75 \mathrm{~cm})$ below the surface.

\section{Calibration}

Three calibration runs were made using a test apparatus in which an insulated test probe was embedded in a test jig with a known volume that was filled with a sample of the test site soil. The weight of this test soil was also determined. At the start of a calibration run the soil was completely dry. Known weights (and hence volumes) of water were added in steps to obtain a curve of percent dry weight vs. dielectric constant. The dielectric constant was calculated using the method described as procedure 2 in the preceding section. This procedure corrects the capacitance measurements made by an insulated probe to values similar to those of an uninsulated probe by assuming a series capacitance in the probe itself. The value of this assumed capacitance is determined by using water as a reference material. The actual equations used for these calculations are shown in Table 6. After all three calibration runs were completed, it was discovered that a procedural error invalidated the data taken in run 1. Since this data had to be rejected, calibration equations were generated for run 2 and run 3 . A composite equation using data from 
Table 6. Equations used for calibration runs.

$\begin{aligned} C & =-3.1831 \times 10^{-11} \times V_{\text {ref }} \times \sin \left(V_{\text {ph }}\right) / V_{\text {div }} \\ C_{\text {cable }} & =1.04 \times 10^{-12} \\ C_{\text {air }} & =3.5 \times 10^{-12} \\ C_{\text {meas }} & =C-C_{\text {cable }} \\ C_{\text {probe }} & =63.2 \times 10^{-12} \times C_{\text {meas }} /\left[\left(63.2 \times 10^{-12}\right)-C_{\text {meas }}\right] \\ \varepsilon & =C_{\text {probe }} / C_{\text {air }}\end{aligned}$

Notes:

$V_{\text {ref }}, V_{\text {diff }}$ and $V_{\mathrm{ph}}$ are the actual values read as the raw field data.

$C_{\text {cable }}$ is the small offset capacitance that corrects for a minor unnulled portion of the cable.

The $63.2 \times 10^{-12} \mathrm{~F}$ is the series capacitance of the insulation on the probe.

The $-3.1831 \times 10^{-11}$ in the first equation is from $1 / R \omega$ $=1 / 500 \times 2 \times \pi \times 10 \times 10^{6}$. The minus sign corrects the minus value for $V_{\mathrm{ph}}$ to yield a positive capacitance value.

Table 7. Calibration run 2, GSB test site.

Dry weight $=65.9 \mathrm{~g}$

Volume $=48 \mathrm{~cm}^{3}$

Insulated probe: Box 1 , probe circuit 1 (nulled) $C_{\text {air }}=3.2$

$\begin{array}{ccc}\text { Dielectric } & \text { Weight of } & \text { Percent of } \\ \text { constant } & \text { water added } & \text { dry weight }\end{array}$

Low end

$\begin{array}{rrr}2.10 \text { (dry) } & 0.00 & 0.0 \\ 2.22 & 0.63 & 1.0 \\ 2.92 & 1.26 & 1.9 \\ 5.22 & 1.89 & 2.9 \\ 6.63 & 2.52 & 3.8 \\ 7.90 & 3.10 & 4.7 \\ 9.28 & 3.73 & 5.7 \\ 10.76 & 4.36 & 6.6 \\ 11.68 & 4.99 & 7.6 \\ 12.17 & 5.62 & 8.5\end{array}$

Midrange

$\begin{array}{rrr}12.88 & 6.25 & 9.5 \\ 13.42 & 6.88 & 10.4 \\ 13.61 & 7.51 & 11.4 \\ 13.91 & 8.14 & 12.4 \\ 14.29 & 8.77 & 13.3 \\ 14.20 & 9.40 & 14.3 \\ 14.61 & 10.03 & 15.2 \\ 15.13 & 10.66 & 16.2 \\ 15.60 & 11.29 & 17.1\end{array}$

High range

\begin{tabular}{lll}
16.36 & 11.92 & 18.1 \\
17.05 & 12.55 & 19.0 \\
17.55 & 13.18 & 20.0 \\
18.12 & 13.81 & 21.0 \\
\hline
\end{tabular}

both of these runs was also generated. Box 1 and probe circuit 1 were used for all calibration runs.

Actual data points for each of these calibration curves are shown in Tables 7 and 8. Since the calibration curves were quite nonlinear, calibration equations for the two calibration runs plus the combination of both runs were generated for three ranges of dielectric constant: low end, midrange, and high range. These calibration equations are shown in Table 9 (for percent dry weight) and Table 10 (for percent volume). Other pertinent soil data, such as each sample's dry weight and volume, are also shown. Note that this procedure is primarily a volume-calibration method, and the percent dry weights were calculated by using the density of the test soil, not by using the actual density of soils at the test site.

Table 8. Calibration run 3, GSB test site.

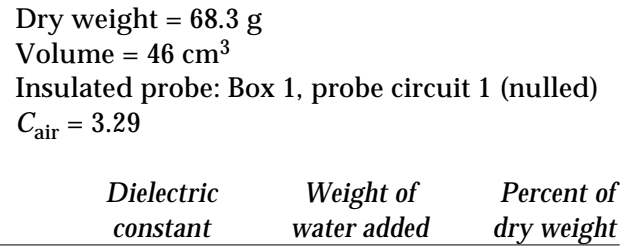

Low end

$\begin{array}{lll}2.07 \text { (dry) } & 0.00 & 0.0 \\ 2.47 & 0.63 & 1.0 \\ 2.89 & 1.26 & 1.8 \\ 3.98 & 1.89 & 2.8 \\ 5.36 & 2.52 & 3.7 \\ 6.64 & 3.15 & 4.6 \\ 7.77 & 3.78 & 5.5 \\ 9.19 & 4.41 & 6.4 \\ 10.52 & 5.05 & 7.4 \\ 11.34 & 5.68 & 8.3\end{array}$

Midrange

$\begin{array}{rrr}11.95 & 6.31 & 9.2 \\ 12.23 & 6.94 & 10.2 \\ 12.73 & 7.57 & 11.1 \\ 13.44 & 8.20 & 12.0 \\ 13.90 & 8.83 & 12.9 \\ 14.27 & 9.46 & 13.8 \\ 14.58 & 10.09 & 14.8 \\ 15.10 & 10.72 & 15.7 \\ 15.63 & 11.35 & 16.6\end{array}$

High range

\begin{tabular}{lll}
15.97 & 11.98 & 17.5 \\
16.44 & 12.61 & 18.5 \\
17.01 & 13.24 & 19.40 \\
17.58 & 13.81 & 20.20 \\
\hline
\end{tabular}


Table 9. Percent dry weight.

\begin{tabular}{|c|c|c|c|}
\hline Low end & 2 to 12.5 & \multicolumn{2}{|c|}{ Calibration runs } \\
\hline Run 2 & $\% D W=0.72834 K-0.89248$ & 10 points & \\
\hline Run 3 & $\% D W=0.81027 \mathrm{~K}-0.89230$ & 10 points & $r=0.992$ \\
\hline Both & $\% D W=0.75435 \mathrm{~K}-0.81060$ & 20 points & $r=0.985$ \\
\hline Midrange & 12.6 to 15.7 & & \\
\hline Run 2 & $\% D W=3.01952 K-29.51577$ & 9 points & $r=0.98$ \\
\hline Run 3 & $\% D W=1.96994 K-14.18193$ & 9 points & $r=0.99$ \\
\hline Both & $\% D W=2.23573 K-18.11893$ & 18 points & $r=0.96$ \\
\hline High range & 15.8 and above & & \\
\hline Run 2 & $\% D W=1.66865 \mathrm{~K}-9$ & 4 points & $r=0.99$ \\
\hline Run 3 & $\% D W=1.65982 K-8.90202$ & 4 points & $r=0.996$ \\
\hline Both & $\% D W=1.59654 K-7.94469$ & 8 points & $r=0.99$ \\
\hline
\end{tabular}

$K=$ measured dielectric constants

Table 10. Percent volume.

\begin{tabular}{lccc} 
Low end & \multicolumn{2}{c}{2 to 12.5} & \multicolumn{2}{c}{ Calibration runs } \\
\hline $\begin{array}{l}\text { Run 2 } \\
\text { Run 3 }\end{array}$ & $\% V=1.00431 K-1.27854$ & $n=10$ & $r=0.990$ \\
Both & $\% V=1.20894 K-1.36324$ & $n=10$ & $r=0.992$ \\
& & $n=20$ & $r=0.973$ \\
Midrange & 12.6 to 15.7 & & \\
\hline Run 2 & $\% V=4.16044 K-40.74224$ & $n=9$ & $r=0.982$ \\
Run 3 & $\% V=2.93798 K-21.23448$ & $n=9$ & $r=0.997$ \\
Both & $\% V=3.08706 K-24.40191$ & $n=18$ & $r=0.920$ \\
High range & $\quad 15.8$ and above & & \\
\hline Run 2 & $\% V=2.30714 K-13.04434$ & $n=4$ & $r=0.997$ \\
Run 3 & $\% V=2.47365 K-13.38361$ & $n=4$ & $r=0.997$ \\
Both & $\% V=1.68080 K-1.165411$ & $n=8$ & $r=0.702$ \\
\hline
\end{tabular}

than this rain event, the soil moisture drops off as expected with the sharp decline caused by the onset of freezing conditions. As expected, the probe at the 6-in. depth froze first, followed by the 12- and then the 18-in. probes. The curves of soil moisture and temperature verify that this was in fact the case (Fig. 4, 5, and 6).

The data indicate that not all the available moisture became frozen. Since the coldest temperatures recorded during the entire winter never went below $-6^{\circ} \mathrm{C}$ (at the 6-in. depth, and even warmer at the 12- and 18-in. depths), in addition to the fact that there were several rain events during the winter, it is possible that this is in fact the case. Other researchers have noted that unfrozen water exists in soils below $0^{\circ} \mathrm{C}$.

The curves in Figures 4 through 7 and the percent soil moisture contents shown in Tables 11,12 , and 13 are based on the dry soil densities of the test soils in the calibration jig, not on the dry soil densities at the test site. For example, a typical dry density for soils in the test site area might be 1.7 or so. If this density is representative of the site, then all soil moisture contents shown in these graphs and tables would be too large and should be reduced by the ratio of the calibration densities to the test site densities (1.425/1.7, or 0.838 on average). Note that a year later it is still possible to correct the soil moisture figures in these graphs and tables just by finding the average dry density of the soil at the test site.

The data from these tests are actual soil moisture measurements determined by mea-

\section{TEST RESULTS}

Using the procedure described, curves of soil moisture in percent dry weight vs. elapsed time for 6,12 , and 18 in. are shown in Figures 4, 5, and 6. The temperature data are also shown for each depth. The data used to generate these curves are in Tables 11, 12, and 13. Figure 7 presents a comparison of moisture content at the three depths during the entire freeze-thaw cycle of the winter season.

All three summation curves in Figure 7 show a gradual decline in moisture content, starting in early December, that takes a sudden sharp rise in mid-December due to a heavy rain that occurred over a 36-hour period. Other

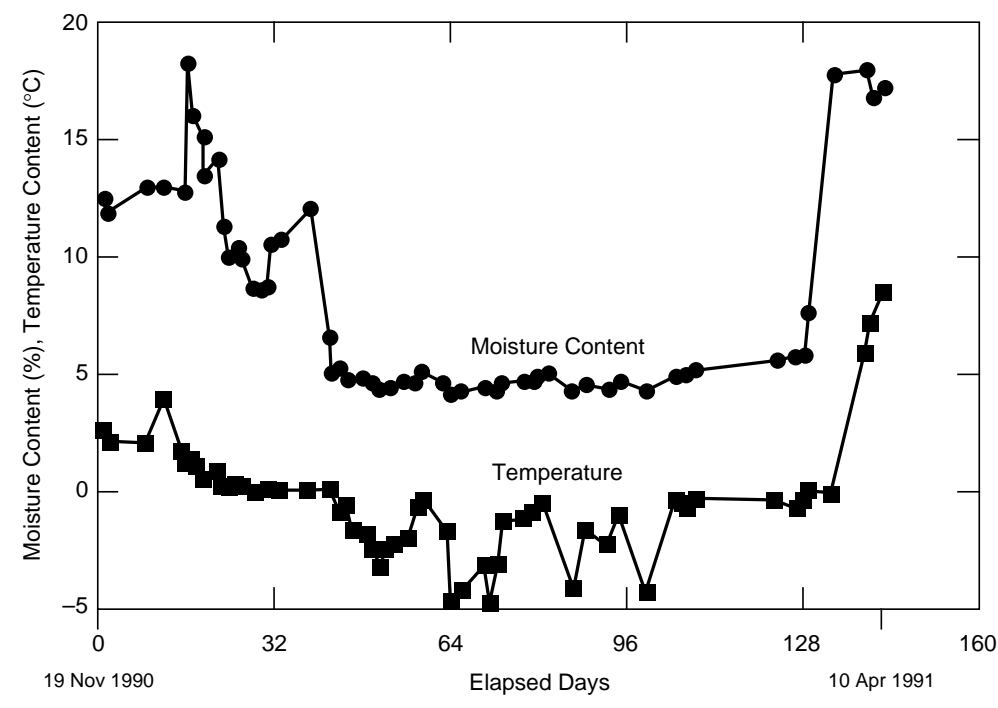

Figure 4. Temperature and percent dry weight vs. elapsed days at 6-in . depth; GSB site. 

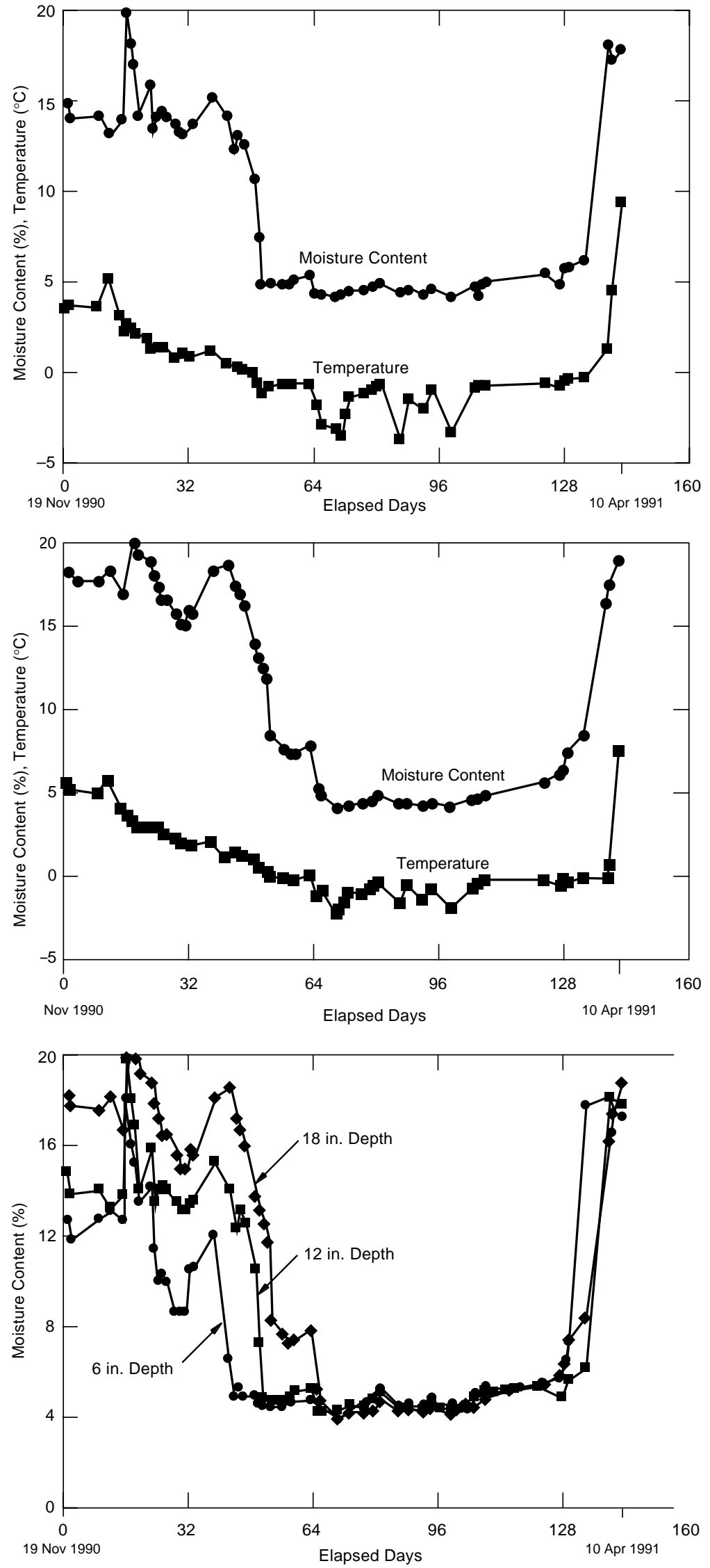

Figure 5. Temperature and percent dry weight vs. elapsed days at 12-in. depth; GSB site.

Figure 6. Temperature and percent dry weight us. elapsed days at 18-in. depth; GSB site.
Figure 7. Moisture content vs. elapsed days at all three depths; GSB site. 
Table 11. GSB test site, 6-in. depth.

\begin{tabular}{|c|c|c|c|c|c|c|}
\hline \multirow{2}{*}{$\begin{array}{l}\text { Elapsed } \\
\text { days }\end{array}$} & \multirow[b]{2}{*}{ Date } & \multirow{2}{*}{$\begin{array}{c}\text { Dielectric } \\
\text { constant }\end{array}$} & \multirow[b]{2}{*}{ Temp. } & \multicolumn{3}{|c|}{ Moisture content (\% dry weight) } \\
\hline & & & & Run 2 & Run 3 & Both \\
\hline 1 & 19 Nov 90 & 13.7 & 2.4 & 11.9 & 12.8 & 12.5 \\
\hline 2 & 20 Nov & 13.4 & 2.1 & 10.9 & 12.2 & 11.8 \\
\hline 9 & $27 \mathrm{Nov}$ & 13.8 & 1.9 & 12.2 & 13.0 & 12.7 \\
\hline 12 & 30 Nov & 13.9 & 3.8 & 12.5 & 13.2 & 13.0 \\
\hline 15 & $3 \mathrm{Dec}$ & 13.8 & 1.6 & 12.2 & 13.0 & 12.7 \\
\hline 16 & $4 \mathrm{Dec}$ & 16.3 & 1.0 & 17.9 & 18.2 & 18.1 \\
\hline 17 & $5 \mathrm{Dec}$ & 15.3 & 1.3 & 16.7 & 16.0 & 16.1 \\
\hline 18 & $6 \mathrm{Dec}$ & 14.9 & 1.0 & 15.5 & 15.2 & 15.2 \\
\hline 19 & $7 \mathrm{Dec}$ & 14.1 & 0.5 & 13.1 & 13.6 & 13.4 \\
\hline 22 & $10 \mathrm{Dec}$ & 14.4 & 0.7 & 14.0 & 14.2 & 14.1 \\
\hline 23 & $11 \mathrm{Dec}$ & 13.2 & 0.1 & 10.3 & 11.8 & 11.4 \\
\hline 24 & $12 \mathrm{Dec}$ & 12.6 & 0.0 & 8.5 & 10.6 & 10.1 \\
\hline 25 & $13 \mathrm{Dec}$ & 12.7 & 0.1 & 8.8 & 10.8 & 10.3 \\
\hline 26 & $14 \mathrm{Dec}$ & 12.6 & 0.1 & 8.5 & 10.6 & 10.1 \\
\hline 29 & $17 \mathrm{Dec}$ & 12.4 & -0.2 & 8.1 & 9.2 & 8.5 \\
\hline 30 & $18 \mathrm{Dec}$ & 12.5 & -0.2 & 8.2 & 9.2 & 8.6 \\
\hline 31 & $19 \mathrm{Dec}$ & 12.5 & -0.1 & 8.2 & 9.2 & 8.6 \\
\hline 32 & $20 \mathrm{Dec}$ & 12.8 & -0.1 & 9.1 & 11.0 & 10.5 \\
\hline 33 & $21 \mathrm{Dec}$ & 12.8 & -0.1 & 9.1 & 11.0 & 10.5 \\
\hline 38 & $26 \mathrm{Dec}$ & 13.5 & -0.1 & 11.2 & 12.4 & 12.1 \\
\hline 42 & $31 \mathrm{Dec}$ & 9.8 & -0.1 & 6.2 & 7.0 & 6.6 \\
\hline 44 & 2 Jan 91 & 7.6 & -0.8 & 4.6 & 5.3 & 4.9 \\
\hline 45 & 3 Jan & 8.0 & -0.7 & 4.9 & 5.6 & 5.2 \\
\hline 46 & 4 Jan & 7.5 & -1.7 & 4.6 & 5.2 & 4.8 \\
\hline 49 & 7 Jan & 7.5 & -1.8 & 4.6 & 5.2 & 4.8 \\
\hline 50 & 8 Jan & 7.2 & -2.5 & 4.4 & 4.9 & 4.6 \\
\hline 51 & 9 Jan & 6.9 & -3.3 & 4.1 & 4.7 & 4.4 \\
\hline 52 & 10 Jan & 7.0 & -2.3 & 4.2 & 4.8 & 4.5 \\
\hline 53 & 11 Jan & 7.0 & -2.3 & 4.2 & 4.8 & 4.5 \\
\hline 56 & 14 Jan & 7.1 & -2.0 & 4.3 & 4.9 & 4.5 \\
\hline 58 & 16 Jan & 7.2 & -0.6 & 4.4 & 4.9 & 4.6 \\
\hline 59 & 17 Jan & 7.9 & -0.4 & 4.9 & 5.5 & 5.1 \\
\hline 63 & 21 Jan & 7.2 & -1.8 & 4.4 & 4.9 & 4.6 \\
\hline 65 & 23 Jan & 6.6 & -5.9 & 3.9 & 4.5 & 4.2 \\
\hline 66 & 24 Jan & 6.7 & -4.2 & 4.0 & 4.5 & 4.2 \\
\hline 70 & $28 \mathrm{Jan}$ & 6.8 & -3.1 & 4.1 & 4.6 & 4.3 \\
\hline 71 & 29 Jan & 6.7 & -4.9 & 4.0 & 4.5 & 4.2 \\
\hline 72 & 30 Jan & 6.8 & -3.1 & 4.1 & 4.6 & 4.3 \\
\hline 73 & 31 Jan & 7.1 & -1.3 & 4.3 & 4.9 & 4.5 \\
\hline 77 & 4 Feb & 7.2 & -1.2 & 4.4 & 4.9 & 4.6 \\
\hline 79 & $6 \mathrm{Feb}$ & 7.5 & -0.9 & 4.6 & 5.2 & 4.8 \\
\hline 80 & 7 Feb & 7.8 & -0.7 & 4.8 & 5.4 & 5.1 \\
\hline 81 & $8 \mathrm{Feb}$ & 7.9 & -0.5 & 4.9 & 5.5 & 5.1 \\
\hline 86 & $13 \mathrm{Feb}$ & 6.8 & -4.0 & 4.1 & 4.6 & 4.3 \\
\hline 88 & $15 \mathrm{Feb}$ & 7.1 & -1.7 & 4.3 & 4.9 & 4.5 \\
\hline 92 & $19 \mathrm{Feb}$ & 7.0 & -2.2 & 4.2 & 4.8 & 4.5 \\
\hline 94 & $21 \mathrm{Feb}$ & 7.4 & -1.0 & 4.5 & 5.1 & 4.8 \\
\hline 99 & $26 \mathrm{Feb}$ & 6.8 & -4.3 & 4.1 & 4.6 & 4.3 \\
\hline 105 & 4 Mar & 7.9 & -0.4 & 4.9 & 5.5 & 5.1 \\
\hline 106 & 5 Mar & 7.9 & -0.5 & 4.9 & 5.5 & 5.1 \\
\hline 107 & 6 Mar & 8.1 & -0.6 & 5.0 & 5.7 & 5.3 \\
\hline 108 & 7 Mar & 8.1 & -0.2 & 5.0 & 5.7 & 5.3 \\
\hline 123 & $22 \mathrm{Mar}$ & 8.4 & -0.4 & 5.2 & 5.9 & 5.5 \\
\hline 127 & $26 \mathrm{Mar}$ & 8.8 & -0.6 & 5.5 & 6.2 & 5.8 \\
\hline 128 & 27 Mar & 8.8 & -0.3 & 5.5 & 6.2 & 5.8 \\
\hline 129 & $28 \mathrm{Mar}$ & 11.3 & 0.1 & 7.3 & 8.3 & 7.7 \\
\hline 133 & $1 \mathrm{Apr}$ & 16.1 & -0.1 & 17.6 & 17.8 & 17.8 \\
\hline 139 & $7 \mathrm{Apr}$ & 16.2 & 5.9 & 17.7 & 18.0 & 17.9 \\
\hline 140 & $8 \mathrm{Apr}$ & 15.6 & 7.2 & 17.6 & 16.5 & 16.8 \\
\hline
\end{tabular}


Table 11 (cont'd). GSB test site, 6-in. depth.

\begin{tabular}{lcccccr}
\multirow{2}{*}{$\begin{array}{c}\text { Elapsed } \\
\text { days }\end{array}$} & Date & $\begin{array}{c}\text { Dielectric } \\
\text { constant }\end{array}$ & Temp. & & \multicolumn{3}{c}{ Moisture content (\% dry weight) } \\
\cline { 6 - 7 } & & & & & & \\
142 & 10 Apr & 15.8 & 8.5 & 17.1 & 17.3 & 17.3 \\
148 & $16 \mathrm{Apr}$ & 15.7 & 6.1 & 17.9 & 16.7 & 17.0 \\
149 & $17 \mathrm{Apr}$ & 15.3 & 5.4 & 16.7 & 16.0 & 16.1 \\
154 & $22 \mathrm{Apr}$ & 15.9 & 6.6 & 17.2 & 17.5 & 17.4 \\
155 & $23 \mathrm{Apr}$ & 15.4 & 8.8 & 17.0 & 16.2 & 16.3 \\
156 & 24 Apr & 15.0 & 5.9 & 15.8 & 15.4 & 15.4 \\
162 & 30 Apr & 16.0 & 10.7 & 17.4 & 17.7 & 17.6 \\
169 & 7 May & 15.9 & 9.6 & 17.2 & 17.5 & 17.4 \\
182 & 20 May & 12.6 & & 8.5 & 10.6 & 10.1 \\
186 & 24 May & 10.9 & 19.2 & 7.0 & 7.9 & 7.4 \\
190 & 28 May & 11.1 & 17.9 & 7.2 & 8.1 & 7.6 \\
191 & 29 May & 10.9 & 17.9 & 7.0 & 7.9 & 7.4 \\
193 & 31 May & 13.2 & & 10.3 & 11.8 & 11.4 \\
196 & 3 Jun & 12.5 & 17.2 & 8.2 & 9.2 & 8.6 \\
\hline
\end{tabular}

Table 12. GSB test site, 12-in. depth.

\begin{tabular}{rrrrrrr} 
Elapsed & & & & \multicolumn{3}{c}{ Moisture content $(\%$ dry weight) } \\
\cline { 5 - 7 } days & Date & $\begin{array}{c}\text { Dielectric } \\
\text { constant }\end{array}$ & Temp. & Run 2 & Run 3 & Both \\
\hline & & & & & & \\
1 & 19 Nov 90 & 14.7 & 3.4 & 14.9 & 14.8 & 14.7 \\
2 & 20 Nov & 14.3 & 3.7 & 13.7 & 14.0 & 13.9 \\
9 & 27 Nov & 14.4 & 3.5 & 14.0 & 14.2 & 14.1 \\
12 & 30 Nov & 14.0 & 5.1 & 12.8 & 13.4 & 13.2 \\
15 & 3 Dec & 14.3 & 3.0 & 13.7 & 14.0 & 13.9 \\
16 & 4 Dec & 17.5 & 2.0 & 19.9 & 20.1 & 20.0 \\
17 & 5 Dec & 16.3 & 2.6 & 17.9 & 18.2 & 18.1 \\
18 & 6 Dec & 15.7 & 2.4 & 17.9 & 16.7 & 17.0 \\
19 & 7 Dec & 14.4 & 2.0 & 14.0 & 14.2 & 14.1 \\
22 & 10 Dec & 15.2 & 1.7 & 16.4 & 15.8 & 15.9 \\
23 & 11 Dec & 14.1 & 1.3 & 13.1 & 13.6 & 13.4 \\
24 & 12 Dec & 14.4 & 1.1 & 14.0 & 14.2 & 14.1 \\
25 & 13 Dec & 14.5 & 1.2 & 14.3 & 14.4 & 14.3 \\
26 & 14 Dec & 14.4 & 1.2 & 14.0 & 14.2 & 14.1 \\
29 & 17 Dec & 14.2 & 0.8 & 13.4 & 13.8 & 13.6 \\
30 & 18 Dec & 14.0 & 0.8 & 12.8 & 13.4 & 13.2 \\
31 & 19 Dec & 14.0 & 0.9 & 12.8 & 13.4 & 13.2 \\
32 & 20 Dec & 14.1 & 0.8 & 13.1 & 13.6 & 13.4 \\
33 & 21 Dec & 14.2 & 0.7 & 13.4 & 13.8 & 13.6 \\
38 & 26 Dec & 14.9 & 1.1 & 15.5 & 15.2 & 15.2 \\
42 & 31 Dec & 14.4 & 0.5 & 14.0 & 14.2 & 14.1 \\
44 & 2 Jan 91 & 13.6 & 0.3 & 11.5 & 12.6 & 12.3 \\
45 & 3 Jan & 14.0 & 0.3 & 12.8 & 13.4 & 13.2 \\
46 & 4 Jan & 13.7 & 0.1 & 11.9 & 12.8 & 12.5 \\
49 & 7 Jan & 12.8 & -0.1 & 9.1 & 11.0 & 10.5 \\
50 & 8 Jan & 10.7 & -0.7 & 6.9 & 7.8 & 7.3 \\
51 & 9 Jan & 7.5 & -1.2 & 4.6 & 5.2 & 4.8 \\
52 & 10 Jan & 7.5 & -0.9 & 4.6 & 5.2 & 4.8 \\
53 & 11 Jan & 7.4 & -0.8 & 4.5 & 5.1 & 4.8 \\
56 & 14 Jan & 7.3 & -0.6 & 4.4 & 5.0 & 4.7 \\
58 & 16 Jan & 7.5 & -0.7 & 4.6 & 5.2 & 4.8 \\
59 & 17 Jan & 7.9 & -0.6 & 4.9 & 5.5 & 5.1 \\
63 & 21 Jan & 8.1 & -0.6 & 5.0 & 5.7 & 5.3 \\
65 & 23 Jan & 6.7 & -1.8 & 4.0 & 4.5 & 4.2 \\
66 & 24 Jan & 6.7 & -2.9 & 4.0 & 4.5 & 4.2 \\
70 & 28 Jan & 6.6 & -3.2 & 3.9 & 4.5 & 4.2 \\
71 & 29 Jan & 6.6 & -3.5 & 3.9 & 4.5 & 4.2 \\
72 & 30 Jan & 6.7 & -2.2 & 4.0 & 4.5 & 4.2
\end{tabular}


Table 12 (cont'd). GSB test site, 12-in. depth.

\begin{tabular}{|c|c|c|c|c|c|c|}
\hline \multirow{2}{*}{$\begin{array}{c}\text { Elapsed } \\
\text { days }\end{array}$} & \multirow[b]{2}{*}{ Date } & \multirow{2}{*}{$\begin{array}{c}\text { Dielectric } \\
\text { constant }\end{array}$} & \multirow[b]{2}{*}{ Temp. } & \multicolumn{3}{|c|}{ Moisture content (\% dry weight) } \\
\hline & & & & Run 2 & Run 3 & Both \\
\hline 73 & 31 Jan & 7.0 & -1.3 & 4.2 & 4.8 & 4.5 \\
\hline 77 & $4 \mathrm{Feb}$ & 7.0 & -1.2 & 4.2 & 4.8 & 4.5 \\
\hline 79 & $6 \mathrm{Feb}$ & 7.3 & -1.0 & 4.4 & 5.0 & 4.7 \\
\hline 80 & $7 \mathrm{Feb}$ & 7.5 & -0.8 & 4.6 & 5.2 & 4.8 \\
\hline 81 & $8 \mathrm{Feb}$ & 7.6 & -0.6 & 4.6 & 5.3 & 4.9 \\
\hline 86 & $13 \mathrm{Feb}$ & 6.7 & -3.7 & 4.0 & 4.5 & 4.2 \\
\hline 88 & 15 Feb & 6.9 & -1.4 & 4.1 & 4.7 & 4.4 \\
\hline 92 & $19 \mathrm{Feb}$ & 6.8 & -2.0 & 4.1 & 4.6 & 4.3 \\
\hline 94 & $21 \mathrm{Feb}$ & 7.2 & -1.0 & 4.4 & 4.9 & 4.6 \\
\hline 99 & $26 \mathrm{Feb}$ & 6.6 & -3.3 & 3.9 & 4.5 & 4.2 \\
\hline 105 & 4 Mar & 7.5 & -0.8 & 4.6 & 5.2 & 4.8 \\
\hline 106 & 5 Mar & 6.6 & -0.6 & 3.9 & 4.5 & 4.2 \\
\hline 107 & 6 Mar & 7.6 & -0.7 & 4.6 & 5.3 & 4.9 \\
\hline 108 & 7 Mar & 7.7 & -0.6 & 4.7 & 5.3 & 5.0 \\
\hline 123 & $22 \mathrm{Mar}$ & 8.2 & -0.5 & 5.1 & 5.8 & 5.4 \\
\hline 127 & $26 \mathrm{Mar}$ & 7.5 & -0.6 & 4.6 & 5.2 & 4.8 \\
\hline 128 & $27 \mathrm{Mar}$ & 8.6 & -0.3 & 5.4 & 6.1 & 5.7 \\
\hline 129 & $28 \mathrm{Mar}$ & 8.6 & -0.4 & 5.4 & 6.1 & 5.7 \\
\hline 133 & $1 \mathrm{Apr}$ & 9.3 & -0.3 & 5.9 & 6.6 & 6.2 \\
\hline 139 & $7 \mathrm{Apr}$ & 16.3 & 1.2 & 17.9 & 18.2 & 18.1 \\
\hline 140 & $8 \mathrm{Apr}$ & 15.8 & 4.5 & 17.1 & 17.3 & 17.3 \\
\hline 142 & $10 \mathrm{Apr}$ & 16.1 & 9.4 & 17.6 & 17.8 & 17.8 \\
\hline 148 & $16 \mathrm{Apr}$ & 15.5 & 5.8 & 17.3 & 16.4 & 16.5 \\
\hline 149 & 17 Apr & 15.3 & 6.0 & 16.7 & 16.0 & 16.1 \\
\hline 154 & $22 \mathrm{Apr}$ & 15.9 & 6.6 & 17.2 & 17.5 & 17.4 \\
\hline 155 & $23 \mathrm{Apr}$ & 15.5 & 6.7 & 17.3 & 16.4 & 16.5 \\
\hline 156 & $24 \mathrm{Apr}$ & 14.9 & 6.8 & 15.5 & 15.2 & 15.2 \\
\hline 162 & $30 \mathrm{Apr}$ & 15.7 & 11.2 & 17.9 & 16.7 & 17.0 \\
\hline 169 & 7 May & 16.2 & 10.1 & 17.7 & 18.0 & 17.9 \\
\hline 182 & 20 May & 13.9 & & 12.5 & 13.2 & 13.0 \\
\hline 186 & 24 May & 12.6 & 16.4 & 8.5 & 10.6 & 10.1 \\
\hline 190 & 28 May & 12.5 & 17.1 & 8.2 & 9.2 & 8.6 \\
\hline 191 & 29 May & 12.6 & 17.8 & 8.5 & 10.6 & 10.1 \\
\hline 193 & 31 May & 12.9 & & 9.4 & 11.2 & 10.7 \\
\hline 196 & 3 Jun & 13.3 & 18.2 & 10.6 & 12.0 & 11.6 \\
\hline
\end{tabular}

Table 13. GSB test site, 18-in. depth.

\begin{tabular}{|c|c|c|c|c|c|c|}
\hline \multirow{2}{*}{$\begin{array}{c}\text { Elapsed } \\
\text { days }\end{array}$} & \multirow[b]{2}{*}{ Date } & \multirow{2}{*}{$\begin{array}{c}\text { Dielectric } \\
\text { constant }\end{array}$} & \multirow[b]{2}{*}{ Temp. } & \multicolumn{3}{|c|}{ Moisture content (\% dry weight) } \\
\hline & & & & Run 2 & Run 3 & Both \\
\hline 1 & 19 Nov 90 & 16.4 & 5.5 & 18.1 & 18.3 & 18.2 \\
\hline 2 & $20 \mathrm{Nov}$ & 16.1 & 5.2 & 17.6 & 17.8 & 17.8 \\
\hline 9 & $27 \mathrm{Nov}$ & 16.0 & 4.7 & 17.4 & 17.7 & 17.6 \\
\hline 12 & $30 \mathrm{Nov}$ & 16.4 & 5.8 & 18.1 & 18.3 & 18.2 \\
\hline 15 & $3 \mathrm{Dec}$ & 15.6 & 4.2 & 17.6 & 16.5 & 16.8 \\
\hline 16 & $4 \mathrm{Dec}$ & 18.0 & 3.6 & 20.7 & 21.0 & 20.8 \\
\hline 17 & $5 \mathrm{Dec}$ & 18.0 & 3.6 & 20.7 & 21.0 & 20.8 \\
\hline 18 & $6 \mathrm{Dec}$ & 17.5 & 3.4 & 19.9 & 20.1 & 20.0 \\
\hline 19 & $7 \mathrm{Dec}$ & 17.0 & 3.0 & 19.1 & 19.3 & 19.2 \\
\hline 22 & $10 \mathrm{Dec}$ & 16.8 & 2.9 & 18.7 & 19.0 & 18.9 \\
\hline 23 & $11 \mathrm{Dec}$ & 16.2 & 2.8 & 17.7 & 18.0 & 17.9 \\
\hline 24 & $12 \mathrm{Dec}$ & 15.8 & 2.8 & 17.1 & 17.3 & 17.3 \\
\hline 25 & $13 \mathrm{Dec}$ & 15.5 & 2.2 & 17.3 & 16.4 & 16.5 \\
\hline 26 & $14 \mathrm{Dec}$ & 15.5 & 2.3 & 17.3 & 16.4 & 16.5 \\
\hline 29 & $17 \mathrm{Dec}$ & 15.1 & 2.2 & 16.1 & 15.6 & 15.6 \\
\hline 30 & $18 \mathrm{Dec}$ & 14.8 & 2.1 & 15.2 & 15.0 & 15.0 \\
\hline 31 & $19 \mathrm{Dec}$ & 14.8 & 1.7 & 15.2 & 15.0 & 15.0 \\
\hline
\end{tabular}


Table 13 (cont'd). GSB test site, 18-in. depth.

\begin{tabular}{|c|c|c|c|c|c|c|}
\hline \multirow{2}{*}{$\begin{array}{c}\text { Elapsed } \\
\text { days }\end{array}$} & \multirow[b]{2}{*}{ Date } & \multirow{2}{*}{$\begin{array}{l}\text { Dielectric } \\
\text { constant }\end{array}$} & \multirow[b]{2}{*}{ Temp. } & \multicolumn{3}{|c|}{ Moisture content (\% dry weight) } \\
\hline & & & & Run 2 & Run 3 & Both \\
\hline 32 & $20 \mathrm{Dec}$ & 15.2 & 1.9 & 16.4 & 15.8 & 15.9 \\
\hline 33 & $21 \mathrm{Dec}$ & 15.1 & 1.8 & 16.1 & 15.6 & 15.6 \\
\hline 38 & $26 \mathrm{Dec}$ & 16.4 & 1.9 & 18.1 & 18.3 & 18.2 \\
\hline 42 & $31 \mathrm{Dec}$ & 16.6 & 1.1 & 18.4 & 18.7 & 18.6 \\
\hline 44 & 2 Jan 91 & 15.8 & 1.3 & 17.1 & 17.3 & 17.3 \\
\hline 45 & $3 \mathrm{Jan}$ & 15.6 & 1.2 & 17.6 & 16.5 & 16.8 \\
\hline 46 & 4 Jan & 15.3 & 1.1 & 16.7 & 16.0 & 16.1 \\
\hline 49 & 7 Jan & 14.3 & 0.9 & 13.7 & 14.0 & 13.9 \\
\hline 50 & 8 Jan & 14.0 & 0.5 & 12.8 & 13.4 & 13.2 \\
\hline 51 & 9 Jan & 13.7 & 0.3 & 11.9 & 12.8 & 12.5 \\
\hline 52 & 10 Jan & 13.4 & 0.3 & 10.9 & 12.2 & 11.8 \\
\hline 53 & 11 Jan & 12.2 & 0.0 & 8.0 & 9.0 & 8.4 \\
\hline 56 & 14 Jan & 11.2 & -0.2 & 7.3 & 8.2 & 7.6 \\
\hline 58 & 16 Jan & 10.8 & -0.3 & 7.0 & 7.9 & 7.3 \\
\hline 59 & 17 Jan & 10.9 & -0.3 & 7.0 & 7.9 & 7.4 \\
\hline 63 & $21 \mathrm{Jan}$ & 11.4 & -0.1 & 7.4 & 8.3 & 7.8 \\
\hline 65 & $23 \mathrm{Jan}$ & 8.0 & -1.1 & 4.9 & 5.6 & 5.2 \\
\hline 66 & 24 Jan & 7.3 & -0.8 & 4.4 & 5.0 & 4.7 \\
\hline 70 & 28 Jan & 6.4 & -2.2 & 3.8 & 4.3 & 4.0 \\
\hline 71 & 29 Jan & 6.4 & -2.1 & 3.8 & 4.3 & 4.0 \\
\hline 72 & 30 Jan & 6.5 & -1.7 & 3.8 & 4.4 & 4.1 \\
\hline 73 & 31 Jan & 6.6 & -1.0 & 3.9 & 4.5 & 4.2 \\
\hline 77 & $4 \mathrm{Feb}$ & 6.7 & -1.1 & 4.0 & 4.5 & 4.2 \\
\hline 79 & $6 \mathrm{Feb}$ & 6.9 & -0.9 & 4.1 & 4.7 & 4.4 \\
\hline 80 & 7 Feb & 7.3 & -0.7 & 4.4 & 5.0 & 4.7 \\
\hline 81 & $8 \mathrm{Feb}$ & 7.3 & -0.5 & 4.4 & 5.0 & 4.7 \\
\hline 86 & $13 \mathrm{Feb}$ & 6.8 & -1.7 & 4.1 & 4.6 & 4.3 \\
\hline 88 & $15 \mathrm{Feb}$ & 6.8 & -0.7 & 4.1 & 4.6 & 4.3 \\
\hline 92 & $19 \mathrm{Feb}$ & 6.6 & -1.4 & 3.9 & 4.5 & 4.2 \\
\hline 94 & $21 \mathrm{Feb}$ & 6.8 & -0.9 & 4.1 & 4.6 & 4.3 \\
\hline 99 & $26 \mathrm{Feb}$ & 6.5 & -2.0 & 3.8 & 4.4 & 4.1 \\
\hline 105 & 4 Mar & 7.1 & -0.7 & 4.3 & 4.9 & 4.5 \\
\hline 106 & 5 Mar & 7.1 & -0.5 & 4.3 & 4.9 & 4.5 \\
\hline 107 & 6 Mar & 7.2 & -0.6 & 4.4 & 4.9 & 4.6 \\
\hline 108 & 7 Mar & 7.3 & -0.4 & 4.4 & 5.0 & 4.7 \\
\hline 123 & 22 Mar & 8.4 & -0.4 & 5.2 & 5.9 & 5.5 \\
\hline 127 & $26 \mathrm{Mar}$ & 9.1 & -0.6 & 5.7 & 6.5 & 6.1 \\
\hline 128 & 27 Mar & 9.6 & -0.2 & 6.1 & 6.9 & 6.4 \\
\hline 129 & $28 \mathrm{Mar}$ & 11.0 & -0.3 & 7.1 & 8.0 & 7.5 \\
\hline 133 & $1 \mathrm{Apr}$ & 12.3 & -0.2 & 8.1 & 9.1 & 8.5 \\
\hline 139 & $7 \mathrm{Apr}$ & 15.4 & -0.2 & 17.0 & 16.2 & 16.3 \\
\hline 140 & $8 \mathrm{Apr}$ & 15.9 & 0.6 & 17.2 & 17.5 & 17.4 \\
\hline 142 & $10 \mathrm{Apr}$ & 16.8 & 7.7 & 18.7 & 19.0 & 18.9 \\
\hline 148 & 16 Apr & 15.9 & 5.9 & 17.2 & 17.5 & 17.4 \\
\hline 149 & 17 Apr & 16.0 & 5.9 & 17.4 & 17.7 & 17.6 \\
\hline 154 & $22 \mathrm{Apr}$ & 16.8 & 6.4 & 18.7 & 19.0 & 18.9 \\
\hline 155 & $23 \mathrm{Apr}$ & 16.3 & 6.5 & 17.9 & 18.2 & 18.1 \\
\hline 156 & $24 \mathrm{Apr}$ & 15.8 & 7.1 & 17.1 & 17.3 & 17.3 \\
\hline 162 & $30 \mathrm{Apr}$ & 15.0 & 10.9 & 15.8 & 15.4 & 15.4 \\
\hline 169 & 7 May & 16.7 & 9.7 & 18.6 & 18.8 & 18.7 \\
\hline 182 & 20 May & 13.6 & & 11.5 & 12.6 & 12.3 \\
\hline 186 & 24 May & 12.2 & 15.2 & 8.0 & 9.0 & 8.4 \\
\hline 190 & 28 May & 11.8 & 16.3 & 7.7 & 8.7 & 8.1 \\
\hline 191 & 29 May & 12.0 & 17.1 & 7.8 & 8.8 & 8.2 \\
\hline 193 & 31 May & 12.0 & & 7.8 & 8.8 & 8.2 \\
\hline 196 & 3 Jun & 13.3 & 17.9 & 10.6 & 12.0 & 11.6 \\
\hline
\end{tabular}


suring a capacitance and relating that capacitance to the soil moisture through an intermediate calculation of the dielectric constant. It would also have been possible to generate calibration curves that related the capacitance directly to the soil moisture. If this procedure were followed, then each time this method was used to measure soil moisture a new calibration curve of capacitance vs. soil moisture would have to be made. By using dielectric constants in the calibration process it may be possible to find a "universal" calibration equation such as Topp et al. (1980) developed. It may even be possible that the equation of Topp and his colleagues will provide sufficient accuracy to be applied directly to the data generated in this field test program. The original paper by Topp et al. (1980) refers to earlier work in which the frequency dependency of the measurements was examined:

\begin{abstract}
The variables which affect the electrical response in soils are texture, structure, soluble salts, water content, temperature, density, and measurement frequency. Over the frequency range of $1 \mathrm{MHz}$ to $1 \mathrm{GHz}$ the real part of the dielectric constant does not appear to be strongly frequency dependent [Davis and Annan, 1977]. It is therefore unlikely that there exists any relaxation mechanisms which impart strong temperature dependence to the real dielectric constant $K^{\prime}$. Davis and Annan [1977] also indicated that the dielectric loss $K^{\prime \prime}$ was considerably less than $K^{\prime}$ in this frequency range.
\end{abstract}

If this is indeed the case, then the $10 \mathrm{MHz}$ measurements taken in this field test program fit inside the range referred to by Davis and Annan. To examine the possibility that Topp and his colleagues' equation could be used for calculating the soil moisture in this field test program, the calculated dielectric constants were used in their equation (eq 4). The resultant soil moistures are shown in Table 14 along with the average soil moistures as determined by both calibration runs. Table 14 also shows the volumetric soil moisture contents that would have resulted from using the calculated dielectric constants in Roth and his colleagues' equation. For this equation, an average density of 1.425 and a soil specific gravity of 2.70 were used, giving an average porosity of $47.2 \%$. The soil's dielectric constant was assumed to be 2.40. The use of these data yielded the following Roth et al. equation:

$$
\theta=\frac{e^{\left(\ln \varepsilon_{\mathrm{c}}\right) / 2.174}-1.471}{6.52} .
$$

The data in Table 14 were also used to generate the curves of soil moisture (percent by volume) vs. dielectric constant for each of the three equations shown in Figure 8. The data are from the probe at the 6-in. $(15.25-\mathrm{cm})$ depth for the months of November, December, and January.

While these data show some relationship between the soil moisture as found by each of the three methods, there is nevertheless a sizeable difference between values calculated by the Topp et al. and Roth et al. equations for the soil moisture and those the calibration runs measure for the soil moisture content. The most probable explanation of why Topp et al. and Roth et al. agree quite closely but differ by a substantial amount from the calibration runs is explained below.

Both Topp and Roth used time domain reflectometry (TDR) to determine the dielectric constant; this method is essentially a pulsed (high-frequency) velocity measurement method, so these relatively low-frequency $(10-\mathrm{MHz})$ capacitance measurements would produce dielectric constants that would be too large for the TDR equations. These large dielectric constants from the capacitance measurements would thus produce too large a moisture content measurement using TDR equations. (Note that the dielectric constant for soil-water-air mixtures decreases as the measurement frequency increases.)

A closely controlled set of soil tests would be

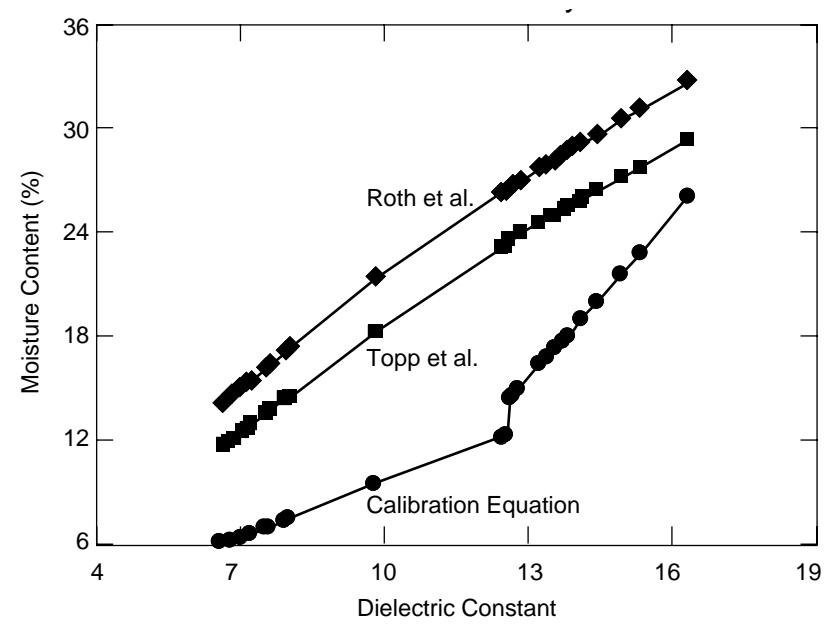

Figure 8. Percent moisture content by volume vs. dielectric constant according to Topp et al., Roth et al., and CRREL calibration equations. 
Table 14. Soil moisture calculations.

\begin{tabular}{|c|c|c|c|c|c|}
\hline \multirow[b]{2}{*}{ Date } & \multirow[b]{2}{*}{$\begin{array}{c}\text { Dielectric } \\
\text { constant }\end{array}$} & \multirow[b]{2}{*}{ Temp } & \multirow{2}{*}{$\begin{array}{c}\text { Moisture by volume } \\
\text { using calibration } \\
\text { equation } \\
(\%)\end{array}$} & \multicolumn{2}{|c|}{$\begin{array}{l}\text { Moisture by volume } \\
\text { using equations of }\end{array}$} \\
\hline & & & & $\begin{array}{c}\text { Topp et al. } \\
(\%)\end{array}$ & $\begin{array}{c}\text { Roth et al. } \\
(\%)\end{array}$ \\
\hline 19 Nov 90 & 13.7 & 2.4 & 17.9 & 25.5 & 28.5 \\
\hline $20 \mathrm{Nov}$ & 13.4 & 2.1 & 17.0 & 25.0 & 28.0 \\
\hline $27 \mathrm{Nov}$ & 13.8 & 1.9 & 18.2 & 25.6 & 28.7 \\
\hline $30 \mathrm{Nov}$ & 13.9 & 3.8 & 18.5 & 25.8 & 28.9 \\
\hline $3 \mathrm{Dec}$ & 13.8 & 1.6 & 18.2 & 25.6 & 28.7 \\
\hline $4 \mathrm{Dec}$ & 16.3 & 1.0 & 26.2 & 29.5 & 32.8 \\
\hline $5 \mathrm{Dec}$ & 15.3 & 1.3 & 22.8 & 28.0 & 31.2 \\
\hline $6 \mathrm{Dec}$ & 14.9 & 1.0 & 21.6 & 27.4 & 30.6 \\
\hline $7 \mathrm{Dec}$ & 14.1 & 0.5 & 19.1 & 26.1 & 29.2 \\
\hline $10 \mathrm{Dec}$ & 14.4 & 0.7 & 20.1 & 26.6 & 29.7 \\
\hline $11 \mathrm{Dec}$ & 13.2 & 0.1 & 16.3 & 24.6 & 27.7 \\
\hline $12 \mathrm{Dec}$ & 12.6 & 0.0 & 14.5 & 23.6 & 26.6 \\
\hline $13 \mathrm{Dec}$ & 12.7 & 0.1 & 14.8 & 23.8 & 26.8 \\
\hline $14 \mathrm{Dec}$ & 12.6 & 0.1 & 14.5 & 23.6 & 26.6 \\
\hline $17 \mathrm{Dec}$ & 12.4 & -0.2 & 12.2 & 23.3 & 26.3 \\
\hline $18 \mathrm{Dec}$ & 12.5 & -0.2 & 12.3 & 23.4 & 26.4 \\
\hline $19 \mathrm{Dec}$ & 12.5 & -0.1 & 12.3 & 23.4 & 26.4 \\
\hline $20 \mathrm{Dec}$ & 12.8 & -0.1 & 15.1 & 24.0 & 27.0 \\
\hline $21 \mathrm{Dec}$ & 12.8 & -0.1 & 15.1 & 24.0 & 27.0 \\
\hline $26 \mathrm{Dec}$ & 13.5 & -0.1 & 17.3 & 25.1 & 28.2 \\
\hline $31 \mathrm{Dec}$ & 9.8 & -0.1 & 9.4 & 18.4 & 21.3 \\
\hline 2 Jan 91 & 7.6 & -0.8 & 7.0 & 13.9 & 16.4 \\
\hline 3 Jan & 8.0 & -0.7 & 7.4 & 14.7 & 17.3 \\
\hline 4 Jan & 7.5 & -1.7 & 6.9 & 13.7 & 16.2 \\
\hline 7 Jan & 7.5 & -1.8 & 6.9 & 13.7 & 16.2 \\
\hline 8 Jan & 7.2 & -2.5 & 6.6 & 13.0 & 15.5 \\
\hline 9 Jan & 6.9 & -3.3 & 6.3 & 12.4 & 14.7 \\
\hline 10 Jan & 7.0 & -2.3 & 6.4 & 12.6 & 15.0 \\
\hline 11 Jan & 7.0 & -2.3 & 6.4 & 12.6 & 15.0 \\
\hline 14 Jan & 7.1 & -2.0 & 6.5 & 12.8 & 15.2 \\
\hline 16 Jan & 7.2 & -0.6 & 6.6 & 13.0 & 15.5 \\
\hline 17 Jan & 7.9 & -0.4 & 7.3 & 14.5 & 17.1 \\
\hline 21 Jan & 7.2 & -1.8 & 6.6 & 13.0 & 15.5 \\
\hline $23 \mathrm{Jan}$ & 6.6 & -5.9 & 5.9 & 11.7 & 14.0 \\
\hline 24 Jan & 6.7 & -4.2 & 6.0 & 11.9 & 14.2 \\
\hline 28 Jan & 6.8 & -3.1 & 6.2 & 12.1 & 14.5 \\
\hline
\end{tabular}

needed to actually determine how well the equations of Topp and Roth and their colleagues could be used to determine soil moisture when using the dielectric constants measured by the method described here rather than those found by the TDR method used by Topp and Roth. However, the data presented in Table 14 and Figure 8 suggest that it is very likely that either Topp et al.'s or Roth et al.'s equation could be modified to work very well with the dielectric constants found using this method of capacitance measurement. Other researchers have found that at low frequencies there is a "break" in the curve and have offered various explanations (see Campbell [1988], for instance).

Another question that might be better answered with a controlled set of laboratory tests is, "What is the expected accuracy of a given soil moisture determination using this particular method for field measurements?" The term "accuracy" is used here to mean the application of a "universal" equation such as those that Topp and Roth and their colleagues developed. This implies that the circuits developed for this measurement method would be used for the laboratory tests and that the measurement frequency would be $10 \mathrm{MHz}$. It should be noted that the circuits used for the tests described here are unique. They are not the standard capacitance bridge measurement systems that have been used to measure and report soil capacitances and dielectric constants in most of the research literature. Instead, these circuits were developed through Dartmouth College specifically to produce DC output voltages that could be 
read out directly in the field and that could be interfaced directly to automatic data logging equipment. The performance limits of these circuits when used with the specific probes that were designed for these test programs have never been determined for the specific application of the measurement of soil moisture.

It should also be noted that the accuracy question may be circumvented entirely by the expedient method of calibrating each measurement system to each individual soil and applying an accuracy limit that is equivalent to the repeatability of the measurement circuit. If such a procedure is used, it would be easier to calibrate directly to a capacitance measurement since a dielectric constant measurement is not required. For individual calibrations such as this, it is probable that acceptable soil moisture measurements could be made with only a single output voltage; for example, soil moisture by percent dry weight vs. $V_{\mathrm{ph}}$. If percent dry weight were required, it would, of course, necessitate tests to find the site's dry soil density, since the capacitance measurement approach is a volume calibration method.

\section{CONCLUSIONS AND RECOMMENDATIONS}

Based on the tests performed to date on this soil moisture measurement system, the following conclusions appear to be supported by the data:

1. The circuits used for these tests provide poor accuracy but are highly repeatable. As such they are perfectly acceptable for capacitance or dielectric constant measurements, provided that an adequate calibration procedure is developed that produces acceptable accuracy.

2. This capacitance method for the determination of soil moisture is capable of producing results that are equally as good as the TDR techniques.

3. Water may be used as a reference material to convert capacitance measurements to dielectric constant measurements. Worst-case accuracies of $\pm 5 \%$ may be reasonably expected using this technique.

4. The circuits used for the tests in this report are more accurate and repeatable when their cable capacitances are nulled.

5. Methanol is a good check on the procedure for dielectric constant measurements. It could also be used as a reference material, the same as water. The calibration procedure would then be to find the dielectric constant from the capacitance mea- surement by solving both the water and the methanol equations simultaneously.

6. It is possible to use insulated probes to make accurate soil moisture measurements, but a careful calibration program is required. The test data (although somewhat small in sample size) indicate that better results are likely possible with the calibration technique of assuming a series capacitance to correct the readings to those that would be expected from uninsulated probes.

7. Data from the insulated probes used for the tests in this report are valid only up to a molarity of $0.01 \mathrm{~N}$ unless calibrated directly for a specific saline soil.

8. The dielectric constants found by using the capacitance measurement procedures together with the circuits and conversion techniques described in this report produce too high a soil moisture measurement when used in the equations of Topp et al. or Roth et al. The probable reason for the high readings is the difference in the frequencies used in this technique and the TDR technique. Nevertheless, these two measurement techniques produce such consistently different values that there is almost certainly a constant multiplier that would allow the use of the Topp et al. or Roth et al. equation and still yield an accuracy equal to that of the gravimetric calibration equations.

9. At a dielectric constant of $K=32$ (the methanol checkpoint), an error of -2.0 in the calculation for this dielectric constant results in an error of $3.3 \%$ in the volume moisture content. The same -2.0 error in the dielectric constant measurement at $K=10$ causes an error of $2.14 \%$ in the soil moisture calculation. Either error seems to be reasonably acceptable, but this does point out the necessity of making dielectric constant measurements as accurately as possible.

Based on these conclusions, the following recommendations seem appropriate:

1. This system works quite well to measure soil moisture. CRREL should continue to develop it and report its use. Ultimately it will prove to be better than TDRs, tensiometers, soil moisture blocks, or similar devices in meeting the ideal performance criteria, listed in the beginning of this report and repeated here:

- Accuracy

- Good long-term stability

- Reliability

- Easily read using untrained observers

- Low cost 
- Easily adapted to dataloggers

- Easily calibrated

- Easily installed

- Ruggedness

- Resistance to environmental parameters such as temperature and humidity.

2. This capacitance method for the measurement of soil moistures can and should be used for both laboratory and field measurement programs, subject to the following limitations:

- Each box or measurement circuit should be individually calibrated to the specific soil in which it will be used.

- For each application, select a specific cable length and use it for all measurements in that particular application.

- Work only with nulled circuits.

- If there is any chance that the salinity of the soil will cause errors, use an insulated probe and analyze the data using the "series capacitance" correction technique using water as the reference material.

3. Start a program to put a $10-\mathrm{MHz}$ circuit in a probe so that cable length is no longer a problem.

4. Start a program to find a better probe insulation.

5. Interface these circuits directly to dataloggers since the accuracy of these circuits is worse than the accuracy of dataloggers themselves. No further testing is needed in this area.

6. Find a second "checkpoint" material besides methanol. This second material should have a dielectric constant of approximately 16 .

7. For small specific applications, a probe and circuit can be calibrated for a specific soil and interfaced to an inexpensive single- or twochannel datalogger (such as the OmniData Datapods).

8. Start a developmental program that explores the possibility of using a simpler, much less expensive circuit (such as the bridged-tee circuit, for instance) and reverse the present measurement philosophy so that the limits of the soils for which this circuit will work properly determine the new circuit and its probe's suitability for the soil moisture measurements under consideration.

This method can and will be improved. In the meantime, the following procedure yields acceptable soil moisture measurements using presently available equipment and the procedures described in this report:
1. Select a cable length.

2. Select a measurement circuit and null it for the selected cable length.

3. Find $C_{\text {air }}$ for each probe/cable combination using water as the reference material.

4. Check $C_{\text {air }}$ for each probe/cable assembly using methanol as the checkpoint material.

5. Install the probes at the field site and at the same time get an average soil density.

6. Calibrate a typical probe/cable combination using a test jig that provides volume moisture contents using field site soils that approximate the dry density that was observed for the test site. This calibration could be either directly in capacitance or in dielectric constant vs. volumetric moisture content.

7. Derive the calibration equations for the volumetric soil moisture contents and use them to solve for the soil moisture at the field site.

8. Use the dry density data from the field site to find percent dry weight if required.

Note that the calibration to actual soils (steps 6 and 7) could be eliminated if a correction ratio for the $10-\mathrm{MHz}$ test frequency were to be determined through a laboratory test program. The equations of either Topp et al. or Roth et al. could then be used as "universal" calibration equations. Note also that the procedures recommended here are general in nature and could be applied equally well to probes of different size as well as for different test frequencies. The only restrictions would be that the probe electrodes must be close enough to have a capacitance of a few picofarads in air but at the same time be large enough to sample a representative amount of soil. For example, a typical TDR probe could be used.

\section{LITERATURE CITED}

Campbell, J.E. (1988) Dielectric properties of moist soils at RF and microwave frequencies. Dartmouth College, Hanover, New Hampshire.

Roth, K., R. Schulin, H. Fluhler, and W. Attinger (1990) Calibration of time domain reflectometry for water content measurement using a composite dielectric approach. Water Resources Research, 26(10): 2267-2273.

Topp, G.C., J.L. Davis, and A.P. Annan (1980) Electromagnetic determination of soil water content: Measurements in coaxial transmission lines. Water Resources Research, 16(3): 574-582. 


\section{APPENDIX A: SAMPLE CALCULATION}

Raw data from the autumn RC tests.

Their statistical summation is also shown.

Electronic tests

Note: $C_{\text {air }}=3.6 \mathrm{pF}$

7 October 1991

\begin{tabular}{lcccrrr} 
Box 2 & $\begin{array}{l}V_{\text {ref }} \\
(V)\end{array}$ & $\begin{array}{l}V_{\text {div }} \\
(V)\end{array}$ & $\begin{array}{c}V_{p h} \\
(\text { degrees })\end{array}$ & $\begin{array}{c}C \\
(p F)\end{array}$ & $\begin{array}{c}C-C_{\text {cable }} \\
(p F)\end{array}$ & $K$ \\
\hline Probe 1 & & & & & & \\
Open & 0.942 & 0.408 & 53.0 & -58.7 & & \\
Cable & 0.965 & 0.800 & -00.6 & 0.4 & & \\
$2.61 \Omega$ & 0.957 & 0.127 & -44.6 & 168.4 & 168.0 & 46.6 \\
$2.49 \mathrm{~K}$ & 0.960 & 0.216 & -65.4 & 128.6 & 128.2 & 35.5 \\
$8.07 \mathrm{~K}$ & 0.968 & 0.618 & -33.7 & 27.7 & 27.3 & 7.6
\end{tabular}

Probe 2

\begin{tabular}{lcccrrr} 
Open & 0.947 & 0.413 & 53.3 & -56.1 & & \\
Cable & 0.968 & 0.805 & -00.6 & 0.4 & & \\
$2.61 \Omega$ & 0.960 & 0.131 & -45.6 & 166.6 & 166.2 & 4.61 \\
$2.49 \mathrm{~K}$ & 0.961 & 0.221 & -65.5 & 125.9 & 125.5 & 34.8 \\
$8.07 \mathrm{~K}$ & 0.970 & 0.625 & -33.6 & 27.3 & 26.9 & 7.5 \\
\hline & & & & & & \\
Box 4 & $(V)$ & $(V)$ & $($ degrees $)$ & $(p F)$ & $(p F)$ & $K$ \\
& & & & & & \\
\hline
\end{tabular}

Probe 1

$\begin{array}{lllll}\text { Open } & 0.980 & 0.418 & 55.4 & -61.4\end{array}$

Cable $\quad 0.995 \quad 0.918 \quad-00.0 \quad$ (00.6)

$\begin{array}{lllllll}2.61 \Omega & 0.988 & 0.138 & -45.5 & 162.5 & 162.5 & 45.1\end{array}$

$\begin{array}{llllrrr}2.49 \mathrm{~K} & 0.990 & 0.246 & -66.7 & 117.6 & 117.6 & 32.6\end{array}$

$\begin{array}{lllllll}8.07 \mathrm{~K} & 0.998 & 0.718 & -35.2 & 25.5 & 25.5 & 7.1\end{array}$

Probe 2

$\begin{array}{lrrrrrr}\text { Open } & 0.981 & 0.428 & 55.5 & -60.1 & & \\ \text { Cable } & 0.998 & 0.912 & -00.0 & (00.4) & & \\ 2.61 \Omega & 0.988 & 0.138 & -45.0 & 163.0 & 163.0 & 45.2 \\ 2.49 \mathrm{~K} & 0.990 & 0.246 & -66.6 & 117.3 & 117.3 & 32.5 \\ 8.07 \mathrm{~K} & 0.998 & 0.718 & -34.8 & 25.5 & 25.5 & 7.1\end{array}$


Raw data from the autumn RC tests

Their statistical summation is also shown.

Electronic tests

Note: $C_{\text {air }}=3.6 \mathrm{pF}$

7 October 1991

\begin{tabular}{lccccrr} 
Box 3 & $\begin{array}{l}V_{\text {ref }} \\
(V)\end{array}$ & $\begin{array}{l}V_{\text {div }} \\
(V)\end{array}$ & $\begin{array}{c}V_{p h} \\
\text { (degrees) }\end{array}$ & $\begin{array}{c}C \\
(p F)\end{array}$ & $\begin{array}{c}C-C_{\text {cable }} \\
(p F)\end{array}$ & $K$ \\
\hline Probe 1 & & & & & & \\
Open & 0.973 & 0.339 & 64.6 & -82.5 & & \\
Cable & 0.991 & 0.656 & -37.6 & 29.3 & & \\
2.61 $\Omega$ & 0.982 & 0.095 & -47.4 & 242.9 & 212.8 & 59.0 \\
2.49 K & 0.995 & 0.177 & -67.5 & 159.2 & 129.8 & 36.0 \\
8.07 K & 0.990 & 0.443 & -53.6 & 57.2 & 27.9 & 7.7
\end{tabular}

Probe 2

\begin{tabular}{lrrrrrr} 
Open & 0.978 & 0.452 & 54.0 & -55.7 & & \\
Cable & 0.995 & 0.663 & -37.8 & 29.3 & & \\
$2.61 \Omega$ & 0.986 & 0.098 & -48.1 & 238.4 & 209.1 & 58.0 \\
$2.49 \mathrm{~K}$ & 0.988 & 0.181 & -67.8 & 160.9 & 131.6 & 36.5 \\
$8.07 \mathrm{~K}$ & 0.990 & 0.443 & -53.6 & 57.2 & 27.6 & 7.7 \\
\hline
\end{tabular}

Test data taken 20 September 1991

Room temperature $=60^{\circ} \mathrm{F}$

\begin{tabular}{|c|c|c|c|c|c|c|}
\hline Box 2 & $\begin{array}{l}V_{r e f} \\
(V)\end{array}$ & $\begin{array}{l}V_{d i v} \\
(V)\end{array}$ & $\begin{array}{c}V_{p h} \\
\text { (degrees) }\end{array}$ & $\begin{array}{c}C \\
(p F)\end{array}$ & $\begin{array}{c}C-C_{\text {cable }} \\
(p F)\end{array}$ & $K$ \\
\hline Probe 1 & \multicolumn{6}{|c|}{$\begin{array}{c}\text { Cables not nulled } \\
\text { Bat: } \mathrm{V}_{+}=8.38 \\
\mathrm{~V}_{-}=8.17\end{array}$} \\
\hline Circuit 1 & 0.847 & 0.446 & -52.2 & 53.4 & 20.2 & 5.6 \\
\hline Circuit 2 & 0.944 & 0.246 & -22.3 & 46.3 & 13.2 & 3.6 \\
\hline Circuit 3 & 0.944 & 0.177 & -68.7 & 158.2 & 125.0 & 34.7 \\
\hline Cable & 0.952 & 0.602 & -41.2 & 33.1 & & \\
\hline Open & 0.936 & 0.330 & 63.1 & -80.5 & & \\
\hline Box 4 & $\begin{array}{l}V_{\text {ref }} \\
(V)\end{array}$ & $\begin{array}{l}V_{\text {div }} \\
(V)\end{array}$ & $\begin{array}{c}V_{p h} \\
\text { (degrees) }\end{array}$ & $\begin{array}{c}C \\
(p F)\end{array}$ & $\begin{array}{c}C-C_{\text {cable }} \\
(p F)\end{array}$ & K \\
\hline Probe 1 & \multicolumn{5}{|c|}{ Cables not nulled } & \\
\hline Circuit 1 & 0.988 & 0.543 & -50.5 & 44.7 & 18.3 & 5.1 \\
\hline Circuit 2 & 0.985 & 0.290 & -20.1 & 37.1 & 10.7 & 3.0 \\
\hline Circuit 3 & 0.983 & 0.210 & -68.6 & 138.7 & 112.3 & 31.1 \\
\hline Cable & 0.991 & 0.732 & -37.8 & 26.4 & & \\
\hline Open & 0.981 & 0.361 & 65.4 & -78.6 & & \\
\hline
\end{tabular}


Test data taken 23 September 1991

Adjusted cables to zero

Room temperature $=75^{\circ} \mathrm{F}$

\begin{tabular}{|c|c|c|c|c|c|c|}
\hline Box 2 & $\begin{array}{l}V_{\text {ref }} \\
(V)\end{array}$ & $\begin{array}{l}V_{\text {div }} \\
(V)\end{array}$ & $\begin{array}{c}V_{p h} \\
\text { (degrees) }\end{array}$ & $\begin{array}{c}C \\
(p F)\end{array}$ & $\begin{array}{c}C-C_{\text {cable }} \\
(p F)\end{array}$ & $K$ \\
\hline Probe 1 & \multicolumn{6}{|c|}{ Adjusted probe 1 from $V_{\mathrm{ph}}=-41.2^{\circ}$ to $-00.3^{\circ}$} \\
\hline $2.61 \Omega$ & 0.962 & 0.128 & -45.1 & 168.4 & 169.3 & 46.9 \\
\hline $2.49 \mathrm{~K}$ & 0.962 & 0.217 & -66.0 & 128.9 & 128.8 & 35.7 \\
\hline $8.07 \mathrm{~K}$ & 0.970 & 0.624 & -33.8 & 27.5 & 27.4 & 7.6 \\
\hline Cable & 0.969 & 0.811 & -00.2 & 0.13 & & \\
\hline Open & 0.946 & 0.422 & +53.1 & -57.1 & & \\
\hline Probe 2 & \multicolumn{6}{|c|}{ Adjusted probe 2 from $V_{\mathrm{ph}}=-37.6^{\circ}$ to $-00.1^{\circ}$} \\
\hline $2.61 \Omega$ & 0.959 & 0.131 & -45.8 & 167.0 & 167.2 & 46.3 \\
\hline $2.49 \mathrm{~K}$ & 0.961 & 0.222 & -65.7 & 125.6 & 125.7 & 34.8 \\
\hline $8.07 \mathrm{~K}$ & 0.967 & 0.631 & -33.0 & 26.6 & 26.7 & 7.4 \\
\hline Cable & 0.965 & 0.810 & -00.2 & -0.13 & & \\
\hline Open & 0.942 & 0.413 & +53.8 & -58.0 & & \\
\hline
\end{tabular}

Test data taken 23 September 1991

Adjusted cables to zero

Room temperature $=75^{\circ} \mathrm{F}$

\section{GSB Site}

\begin{tabular}{ccccccc} 
& $V_{\text {ref }}$ & $V_{\text {div }}$ & $V_{\text {ph }}$ & $C$ & $C-C_{\text {cable }}$ & \\
Box 3 & $(V)$ & $(V)$ & (degrees) & $(p F)$ & $(p F)$ & $K$ \\
\hline
\end{tabular}

Probe 1 Already adjusted to zero-out a cable of a different length. Left adjustment to be correct for that cable.

$\begin{array}{lrrrrrr}2.61 \Omega & 0.976 & 0.097 & -47.2 & 235.0 & 205.7 & 57.0 \\ 2.49 \mathrm{~K} & 0.976 & 0.178 & -67.0 & 160.6 & 131.3 & 36.4 \\ 8.07 \mathrm{~K} & 0.980 & 0.444 & -52.8 & 56.2 & 26.9 & 7.5 \\ \text { Cable } & 0.981 & 0.649 & -37.5 & 29.3 & & \\ \text { Open } & 0.969 & 0.337 & 63.9 & -82.2 & & \end{array}$

\section{Probe 2}

\begin{tabular}{lrrrrrr}
$2.61 \Omega$ & 0.982 & 0.099 & -48.1 & 235.0 & 205.7 & 57.0 \\
$2.49 \mathrm{~K}$ & 0.983 & 0.181 & -67.5 & 159.7 & 130.4 & 36.1 \\
$8.07 \mathrm{~K}$ & 0.986 & 0.449 & -53.3 & 56.0 & 26.8 & 7.4 \\
Cable & 0.989 & 0.659 & -37.8 & 29.3 & & \\
Open & 0.974 & 0.339 & +64.9 & -82.8 & & \\
\hline
\end{tabular}


Copy of test data taken 23 September 1991

\begin{tabular}{ccccccc} 
& $V_{\text {ref }}$ & $V_{\text {div }}$ & $V_{\text {ph }}$ & $C$ & $C-C_{\text {cable }}$ & \\
Box 4 & $(V)$ & $(V)$ & $($ degrees $)$ & $(p F)$ & $(p F)$ & $K$ \\
\hline
\end{tabular}

Probe 1 Adjusted probe 1 from $V_{\mathrm{ph}}=-41.6^{\circ}$ to $-00.2^{\circ}$

$\begin{array}{lrrrrrr}2.61 \Omega & 0.989 & 0.138 & -45.5 & 162.7 & 162.0 & 45.0 \\ 2.49 \mathrm{~K} & 0.989 & 0.245 & -66.9 & 118.2 & 117.6 & 32.6 \\ 8.07 \mathrm{~K} & 0.996 & 0.715 & -38.1 & 27.3 & 26.8 & 7.4 \\ \text { Cable } & 0.995 & 0.923 & -00.9 & 0.54 & & \\ \text { Open } & 0.981 & 0.430 & 55.0 & -59.5 & & \end{array}$

Probe 2

\begin{tabular}{llllcrr}
$2.61 \Omega$ & 0.991 & 0.141 & -45.7 & 160.1 & 158.9 & 44.3 \\
$2.49 \mathrm{~K}$ & 0.992 & 0.250 & -66.3 & 115.0 & 115.5 & 32.0 \\
$8.07 \mathrm{~K}$ & 0.998 & 0.714 & -34.3 & 25.1 & 24.9 & 6.9 \\
Cable & 0.998 & 0.913 & -00.3 & 0.18 & & \\
Open & 0.980 & 0.435 & +55.0 & -58.7 & & \\
\hline
\end{tabular}

Test data taken 26 September 1991

\begin{tabular}{lcccrrr} 
Box 3 & $\begin{array}{l}V_{\text {ref }} \\
(V)\end{array}$ & $\begin{array}{l}V_{\text {div }} \\
(V)\end{array}$ & $\begin{array}{c}V_{p h} \\
(\text { degrees })\end{array}$ & $\begin{array}{c}C \\
(p F)\end{array}$ & $\begin{array}{c}C-C_{\text {cable }} \\
(p F)\end{array}$ & $K$ \\
\hline Probe 1 & \multicolumn{7}{c}{$\begin{array}{l}V_{\mathbf{0}}^{+}=8.397 \\
\end{array}$} & \multicolumn{7}{c}{$V_{\mathbf{o}}^{-}=\mathbf{8 . 1 6 2}$} \\
$2.61 \Omega$ & 0.984 & 0.099 & -47.4 & 232.9 & 232.9 & 56.5 \\
$2.49 \mathrm{~K}$ & 0.984 & 0.179 & -66.2 & 160.1 & 131.0 & 36.3 \\
$8.07 \mathrm{~K}$ & 0.987 & 0.447 & -53.1 & 56.2 & 27.1 & 7.5 \\
Cable & 0.990 & 0.657 & -37.4 & -29.1 & & \\
Open & 0.977 & 0.339 & +64.8 & -83.0 & &
\end{tabular}

Probe 2

\begin{tabular}{lrrrrrr}
$2.61 \Omega$ & 0.980 & 0.100 & -47.8 & 231.1 & 202.3 & 56.1 \\
$2.49 \mathrm{~K}$ & 0.981 & 0.182 & -67.0 & 157.9 & 129.1 & 35.8 \\
$8.07 \mathrm{~K}$ & 0.984 & 0.450 & -53.0 & 55.6 & 26.8 & 7.4 \\
Cable & 0.987 & 0.661 & -37.3 & 28.8 & & \\
Open & 0.973 & 0.338 & +64.8 & -82.9 & & \\
\hline
\end{tabular}

\begin{tabular}{lcccrrr} 
Box 2 & $\begin{array}{l}V_{\text {ref }} \\
(V)\end{array}$ & $\begin{array}{l}V_{\text {div }} \\
(V)\end{array}$ & $\begin{array}{c}V_{p h} \\
(\text { degrees })\end{array}$ & $\begin{array}{c}C \\
(p F)\end{array}$ & $\begin{array}{c}C-C_{\text {cable }} \\
(p F)\end{array}$ & $K$ \\
\hline Probe 1 & \multicolumn{7}{c}{$V^{+}=\mathbf{8 . 3 4 6}$} \\
& \multicolumn{7}{c}{$V_{\text {B }}{ }^{-}=\mathbf{7 . 9 7 7}$} \\
$2.61 \Omega$ & 0.953 & 0.128 & -44.5 & 166.1 & 166.0 & 46.0 \\
$2.49 \mathrm{~K}$ & 0.956 & 0.215 & -65.3 & 128.6 & 128.5 & 35.6 \\
$8.07 \mathrm{~K}$ & 0.965 & 0.625 & -33.6 & 27.2 & 27.1 & 7.5 \\
Cable & 0.960 & 0.809 & -00.1 & 0.0 & & \\
Open & 0.939 & 0.402 & +53.6 & -59.8 & &
\end{tabular}




\begin{tabular}{lccccrr} 
Box 2 & $\begin{array}{l}V_{\text {ref }} \\
(V)\end{array}$ & $\begin{array}{l}V_{\text {div }} \\
(V)\end{array}$ & $\begin{array}{c}V_{p h} \\
\text { (degrees) }\end{array}$ & $\begin{array}{c}C \\
(p F)\end{array}$ & $\begin{array}{c}C-C_{\text {cable }} \\
(p F)\end{array}$ & $K$ \\
\hline Probe 2 & & & & & & \\
& & & & & & \\
$2.61 \Omega$ & 0.958 & 0.958 & -45.5 & 166.0 & 166.1 & 46.0 \\
$2.49 \mathrm{~K}$ & 0.959 & 0.959 & -65.4 & 125.6 & 125.6 & 34.8 \\
8.07 K & 0.965 & 0.965 & -33.4 & 26.8 & 26.9 & 7.4 \\
Cable & 0.966 & 0.966 & +00.1 & -0.1 & & \\
Open & 0.945 & 0.945 & +54.2 & -60.2 & & \\
\hline
\end{tabular}

Test data taken 26 September 1991

\begin{tabular}{|c|c|c|c|c|c|c|}
\hline Box 3 & $\begin{array}{l}V_{r e f} \\
(V)\end{array}$ & $\begin{array}{l}V_{d i v} \\
(V)\end{array}$ & $\begin{array}{c}V_{p h} \\
\text { (degrees) }\end{array}$ & $\begin{array}{c}C \\
(p F)\end{array}$ & $\begin{array}{c}C-C_{\text {cable }} \\
(p F)\end{array}$ & $K$ \\
\hline Probe 1 & \multicolumn{6}{|c|}{$\begin{array}{l}V_{\mathrm{B}}^{+}=8.296 \\
V_{\text {B }}{ }^{-}=8.062\end{array}$} \\
\hline $2.61 \Omega$ & 0.980 & 0.096 & -47.1 & 238.0 & 209.2 & 58.0 \\
\hline $2.49 \mathrm{~K}$ & 0.978 & 0.178 & -67.0 & 161.0 & 132.1 & 36.6 \\
\hline $8.07 \mathrm{~K}$ & 0.983 & 0.445 & -53.0 & 56.1 & 27.3 & 7.5 \\
\hline Cable & 0.985 & 0.657 & -37.2 & 28.8 & & \\
\hline Open & 9.970 & 0.339 & +64.0 & -81.8 & & \\
\hline
\end{tabular}

Probe 2

\begin{tabular}{lllrrrr}
$2.61 \Omega$ & 9.981 & 0.100 & -47.7 & 230.9 & 202.1 & 56.0 \\
$2.49 \mathrm{~K}$ & 9.981 & 0.181 & -66.9 & 158.7 & 130.0 & 36.0 \\
$8.07 \mathrm{~K}$ & 9.987 & 0.451 & -52.9 & 55.6 & 26.7 & 7.4 \\
Cable & 9.989 & 0.664 & -37.4 & 28.8 & & \\
Open & 0.976 & 0.340 & 64.4 & -82.4 & & \\
\hline
\end{tabular}

\begin{tabular}{|c|c|c|c|c|c|c|}
\hline Box 4 & $\begin{array}{l}V_{r e f} \\
(V)\end{array}$ & $\begin{array}{l}V_{d i v} \\
(V)\end{array}$ & $\begin{array}{c}V_{p h} \\
\text { (degrees) }\end{array}$ & $\begin{array}{c}C \\
(p F)\end{array}$ & $\begin{array}{c}C-C_{\text {cable }} \\
(p F)\end{array}$ & K \\
\hline Probe 1 & \multicolumn{6}{|c|}{$\begin{array}{l}V_{\mathrm{B}^{+}}=8.257 \\
V_{\mathrm{B}}^{-}=7.950\end{array}$} \\
\hline $2.61 \Omega$ & 0.989 & 0.140 & -45.5 & 157.6 & 157.1 & 43.5 \\
\hline $2.49 \mathrm{~K}$ & 0.989 & 0.248 & -65.8 & 115.8 & 115.2 & 31.9 \\
\hline $8.07 \mathrm{~K}$ & 0.994 & 0.721 & -34.4 & 24.8 & 24.2 & 6.7 \\
\hline Cable & 0.993 & 0.927 & 00.9 & 0.5 & & \\
\hline Open & 0.978 & 0.431 & +55.4 & -59.4 & & \\
\hline \multicolumn{7}{|l|}{ Probe 2} \\
\hline $2.61 \Omega$ & 0.989 & 0.143 & -44.9 & 155.4 & 155.0 & 43.0 \\
\hline $2.49 \mathrm{~K}$ & 0.989 & 0.251 & -64.4 & 114.0 & 113.6 & 31.5 \\
\hline $8.07 \mathrm{~K}$ & 0.996 & 0.714 & -33.7 & 24.6 & 24.2 & 6.7 \\
\hline Cable & 0.998 & 0.914 & 00.7 & 0.4 & & \\
\hline Open & 0.979 & 0.440 & +55.6 & -58.4 & & \\
\hline
\end{tabular}




\section{Statistical analysis of the performance of the four boxes with a constant known input on the end of a cable.}

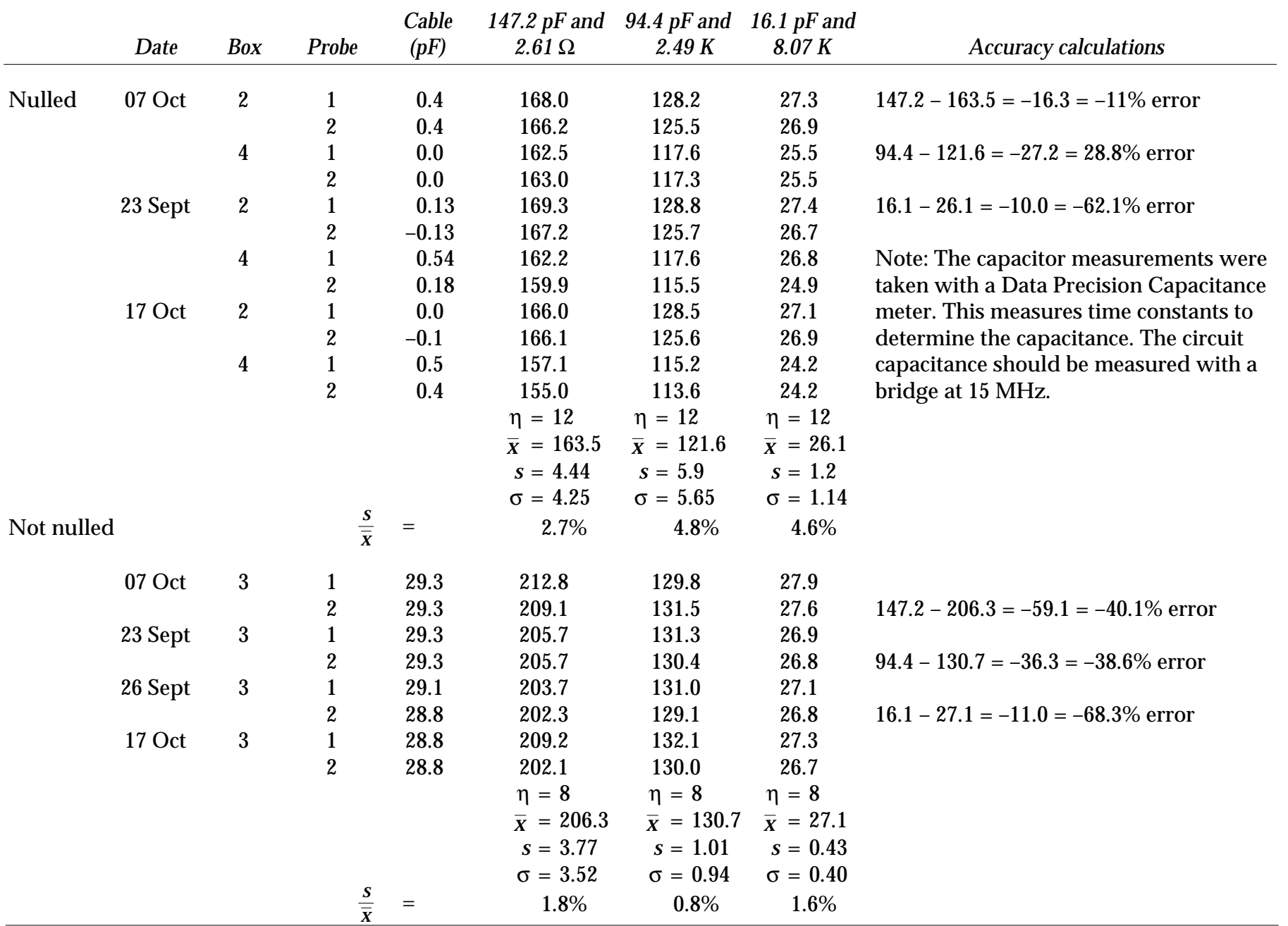




\section{APPENDIX B: RAW DATA FROM PROBE TESTS}

\section{Distilled Water and Methanol}

Box 2. Distilled water, nulled. Probe $1, C_{\mathrm{D}}=1.59 \mathrm{~F}$. Assume $C_{\text {air }}=3.1 \mathrm{pF}, T=21.6^{\circ} \mathrm{C}, K=79.78$.

\begin{tabular}{lcccccc} 
Probe 1 & $\begin{array}{c}V_{\text {ref }} \\
(V)\end{array}$ & $\begin{array}{c}V_{\text {div }} \\
(V)\end{array}$ & $\begin{array}{c}V_{\text {ph }} \\
(\text { degrees })\end{array}$ & $\begin{array}{c}C \\
(p F)\end{array}$ & $\begin{array}{c}C-C_{D} \\
(p F)\end{array}$ & $\varepsilon_{\text {DW }}$ \\
\hline DUM & 0.974 & 0.817 & 2.4 & -1.59 & & \\
A & 0.965 & 0.121 & -76.5 & 246.8 & 248.4 & 80.1 \\
B & 0.965 & 0.121 & -76.5 & 246.7 & 248.3 & 80.1 \\
C & 0.963 & 0.119 & -76.9 & 250.9 & 252.5 & 81.4 \\
D & 0.964 & 0.121 & -76.6 & 246.7 & 248.3 & 80.1 \\
E & 0.963 & 0.124 & -76.7 & 246.6 & 242.2 & 78.1 \\
F & 0.965 & 0.121 & -76.2 & 246.5 & 248.1 & 80.0 \\
G & 0.962 & 0.123 & -76.8 & 242.4 & 244.0 & 78.7 \\
H & 0.965 & 0.121 & -76.5 & 246.8 & 248.4 & 80.1 \\
J & 0.964 & 0.121 & -76.3 & 246.4 & 248.0 & 80.0 \\
K & 0.959 & 0.118 & -76.9 & 251.9 & 253.5 & 81.8 \\
L & 0.965 & 0.120 & -76.9 & 248.8 & 250.4 & 80.8 \\
M & 0.954 & 0.205 & -71.3 & 140.3 & 141.9 & $(45.8)$ INS \\
N & 0.961 & 0.119 & -76.9 & 250.3 & 251.9 & 81.3 \\
O & 0.965 & 0.121 & -76.7 & 247.0 & 248.6 & 80.2 \\
P & 0.965 & 0.117 & -76.4 & 255.2 & 256.8 & 82.9 \\
R & 0.964 & 0.121 & -76.8 & 246.9 & 248.5 & 80.1 \\
S & 0.963 & 0.120 & -76.8 & 248.7 & 250.3 & 80.7 \\
T & 0.964 & 0.121 & -76.5 & 246.6 & 248.2 & 80.0 \\
U & 0.958 & 0.212 & -76.4 & 136.3 & 137.9 & $(44.5)$ INS \\
V & 0.964 & 0.120 & -76.6 & 248.7 & 250.3 & 80.8 \\
W & 0.964 & 0.120 & -76.7 & 248.8 & 250.4 & 80.8 \\
X & 0.964 & 0.120 & -76.8 & 248.9 & 250.5 & 80.8 \\
Y & 0.964 & 0.118 & -76.7 & 253.1 & 254.6 & 82.1 \\
& & & & $\eta=21$ & $\eta=21$ & $\eta=21$ \\
& & & & $\bar{x}=248.0$ & $\bar{x}=249.6$ & $\bar{x}=80.5$ \\
& & & & $s=3.25$ & $s=3.24$ & $s=1.05$ \\
& & & & $\sigma=3.17$ & $\sigma=3.16$ & $\sigma=1.02$ \\
\hline
\end{tabular}

INS $=$ not used for these calculations 
Box 2. Methanol, nulled.

Probe 1, $C_{\mathrm{D}}=1.62 \mathrm{pF}$. Assume $C_{\text {air }}=3.1 \mathrm{pF}$.

\begin{tabular}{|c|c|c|c|c|c|c|}
\hline Probe 1 & $\begin{array}{l}V_{r e f} \\
(V)\end{array}$ & $\begin{array}{l}V_{\text {div }} \\
(V)\end{array}$ & $\begin{array}{c}V_{p h} \\
\text { (degrees) }\end{array}$ & $\begin{array}{c}C \\
(p F)\end{array}$ & $\begin{array}{c}C-C_{D} \\
(p F)\end{array}$ & $\varepsilon_{\text {methanol }}$ \\
\hline DUM & 0.962 & 0.805 & 2.5 & -1.66 & - & - \\
\hline A & 0.960 & 0.293 & -62.4 & 92.4 & 94.0 & 30.3 \\
\hline B & 0.964 & 0.293 & -63.2 & 293.5 & 95.1 & 30.7 \\
\hline C & 0.963 & 0.295 & -62.0 & 91.7 & 93.4 & 30.1 \\
\hline $\mathrm{D}$ & 0.966 & 0.299 & -62.6 & 91.3 & 92.9 & 30.0 \\
\hline $\mathrm{E}$ & 0.968 & 0.306 & -62.1 & 89.0 & 90.6 & 29.2 \\
\hline $\mathrm{F}$ & 0.967 & 0.295 & -62.6 & 92.6 & 94.2 & 30.4 \\
\hline G & 0.968 & 0.297 & -62.8 & 92.3 & 93.9 & 30.3 \\
\hline $\mathrm{H}$ & 0.965 & 0.296 & -62.7 & 92.2 & 93.8 & 30.3 \\
\hline $\mathrm{J}$ & 0.969 & 0.293 & -63.2 & 94.0 & 95.6 & 30.8 \\
\hline $\mathrm{K}$ & 0.969 & 0.294 & -63.1 & 93.6 & 95.2 & 30.7 \\
\hline $\mathrm{L}$ & 0.969 & 0.292 & -63.3 & 94.4 & 96.0 & 31.0 \\
\hline M & 0.971 & 0.371 & -58.0 & 70.6 & 72.3 & (23.3) INS \\
\hline $\mathrm{N}$ & 0.969 & 0.290 & -63.4 & 95.1 & 96.7 & 31.2 \\
\hline $\mathrm{O}$ & 0.970 & 0.295 & -63.0 & 93.2 & 95.0 & 30.6 \\
\hline $\mathrm{P}$ & 0.965 & & & & & \\
\hline $\mathrm{R}$ & 0.971 & 0.301 & -62.5 & 91.1 & 92.7 & 29.9 \\
\hline S & 0.970 & 0.297 & -62.7 & 92.4 & 94.0 & 30.3 \\
\hline $\mathrm{T}$ & 0.971 & 0.301 & -62.5 & 691.1 & 92.7 & 29.9 \\
\hline $\mathrm{U}$ & 0.971 & 0.372 & -58.0 & 70.4 & 72.1 & (23.2) INS \\
\hline $\mathrm{V}$ & 0.970 & 0.294 & -63.2 & 93.6 & 95.2 & 30.7 \\
\hline W & 0.970 & 0.300 & -62.5 & 91.3 & 92.9 & 30.0 \\
\hline$X$ & - & & & & & \\
\hline $\mathrm{Y}$ & 0.970 & 0.289 & -63.4 & 95.5 & 97.1 & 31.3 \\
\hline DUM & 0.976 & 0.819 & 2.4 & $\begin{aligned} & -1.59 \\
\eta & =19 \\
\bar{x} & =92.6 \\
s & =1.58 \\
\sigma & =1.54\end{aligned}$ & $\begin{aligned} & - \\
\eta & =19 \\
\bar{x} & =94.3 \\
s & =1.58 \\
\sigma & =1.54\end{aligned}$ & $\begin{aligned} & - \\
\eta & =19 \\
\bar{x} & =30.4 \\
s & =0.51 \\
\sigma & =0.50\end{aligned}$ \\
\hline
\end{tabular}

INS $=$ not used for these calculations 
Box 4. Distilled water, nulled.

Probe 1, $C_{\mathrm{D}}=2.03 \mathrm{pF}$. Note: $C_{\mathrm{air}}=2.99 \mathrm{pF}$.

\begin{tabular}{lcccccc} 
Probe 1 & $\begin{array}{c}V_{\text {ref }} \\
(V)\end{array}$ & $\begin{array}{c}V_{\text {div }} \\
(V)\end{array}$ & $\begin{array}{c}V_{p h} \\
(\text { degrees })\end{array}$ & $\begin{array}{c}C \\
(p F)\end{array}$ & $\begin{array}{c}C-C_{D} \\
(p F)\end{array}$ & $\varepsilon_{D W}$ \\
\hline DUM & 0.998 & 0.929 & 3.4 & -2.0 & - & - \\
A & 0.984 & 0.132 & -76.6 & 230.8 & 232.8 & 79.7 \\
B & 0.991 & 0.130 & -77.0 & 2236.4 & 238.4 & 81.7 \\
C & 0.991 & 0.129 & -76.6 & 237.9 & 239.9 & 82.1 \\
D & 0.991 & 0.130 & -76.5 & 2235.9 & 238.0 & 81.5 \\
E & 0.991 & 0.135 & -76.2 & 2226.9 & 228.9 & 78.4 \\
F & 0.991 & 0.313 & -76.9 & 2234.5 & 236.5 & 81.0 \\
G & 0.991 & 0.132 & -75.7 & 231.5 & 233.6 & 80.0 \\
H & 0.988 & 0.131 & -77.1 & 234.0 & 236.0 & 80.8 \\
J & 0.991 & 0.130 & -76.5 & 2235.9 & 238.0 & 81.5 \\
K & 0.991 & 0.127 & -75.7 & 2240.1 & 242.2 & 82.9 \\
L & 0.986 & 0.130 & -77.0 & 235.2 & 237.2 & 81.2 \\
M & 0.992 & 0.233 & -71.7 & 128.7 & 130.7 & $(22.7)$ INS \\
N & 0.991 & 0.128 & -76.2 & 8239.3 & 241.3 & 82.6 \\
O & 0.990 & 0.129 & -77.3 & 8238.3 & 240.3 & 82.3 \\
P & 0.989 & 0.125 & -77.1 & 8245.5 & 247.5 & 84.8 \\
R & 0.991 & 0.129 & -76.5 & 8237.8 & 239.8 & 82.1 \\
S & 0.991 & 0.129 & -75.9 & 237.1 & 239.2 & 81.9 \\
T & 0.991 & 0.181 & -76.3 & 2233.9 & 236.0 & 80.8 \\
U & 0.993 & 0.242 & -71.5 & 6237.5 & 125.9 & $(43.1)$ INS \\
V & 0.991 & 0.130 & -77.0 & 236.4 & 238.4 & 81.7 \\
W & 0.991 & 0.129 & -76.3 & 237.5 & 239.6 & 82.0 \\
X & 0.991 & 0.130 & -75.7 & 235.1 & 237.1 & 81.2 \\
Y & 0.991 & 0.127 & -76.8 & 241.8 & 243.8 & 83.5 \\
& & & & $\eta=21$ & $\eta=21$ & $\eta=21$ \\
& & & & $\bar{x}=236.3$ & $\bar{x}=238.3$ & $\bar{x}=81.6$ \\
& & & & $s=3.92$ & $s=3.92$ & $s=1.34$ \\
& & & & $\sigma=3.83$ & $\sigma=3.83$ & $\sigma=1.31$ \\
\hline $\mathrm{INS}$ & & & & & &
\end{tabular}

INS $=$ not used for these calculations 
Box 3. Distilled water, not nulled.

Probe $1, T=21.6^{\circ} \mathrm{C} . C_{\mathrm{D}}=27.2 \mathrm{pF} . C_{\text {air }}=4.1 \mathrm{pF}$.

\begin{tabular}{lcccccc} 
Probe 1 & $\begin{array}{l}V_{\text {ref }} \\
(V)\end{array}$ & $\begin{array}{c}V_{\text {div }} \\
(V)\end{array}$ & $\begin{array}{c}V_{p h} \\
(\text { degrees })\end{array}$ & $\begin{array}{c}C \\
(p F)\end{array}$ & $\begin{array}{c}C-C_{D} \\
(p F)\end{array}$ & $\varepsilon_{\text {DW }}$ \\
\hline DUM & 0.994 & 0.671 & -35.2 & 26.9 & - & - \\
A & 0.989 & 0.084 & -75.5 & 362.8 & 81.5 & - \\
B & 0.984 & 0.085 & -75.1 & 256.1 & 328.9 & 79.8 \\
C & 0.976 & 0.084 & -74.3 & 356.0 & 328.8 & 79.8 \\
D & 0.989 & 0.084 & -75.4 & 363.0 & 335.8 & 81.5 \\
E & 0.987 & 0.089 & -75.1 & 341.1 & 313.9 & 76.2 \\
F & 0.990 & 0.084 & -75.1 & 362.5 & 335.3 & 81.4 \\
G & 0.989 & 0.086 & -75.1 & 353.7 & 326.5 & 79.3 \\
H & 0.986 & 0.084 & -75.2 & 361.2 & 334.0 & 81.1 \\
J & 0.988 & 0.084 & -75.2 & 362.0 & 334.8 & 81.3 \\
K & 0.988 & 0.081 & -75.3 & 378.5 & 348.3 & 84.6 \\
L & 0.990 & 0.083 & -75.0 & 366.7 & 339.5 & 82.4 \\
M & 0.984 & 0.169 & -72.6 & 176.8 & 149.7 & $(26.3)$ INS \\
N & 0.981 & 0.033 & -74.9 & 363.2 & 336.0 & 81.6 \\
O & 0.987 & 0.085 & -75.6 & 358.0 & 330.8 & 80.3 \\
P & 0.986 & 0.078 & -75.5 & 398.5 & 362.3 & 88.0 \\
R & 0.987 & 0.082 & -75.5 & 370.9 & 343.7 & 83.4 \\
S & 0.989 & 0.083 & -75.1 & 366.5 & 339.3 & 92.4 \\
T & 0.990 & 0.085 & -74.6 & 357.4 & 330.2 & 80.2 \\
U & 0.981 & 0.173 & -72.1 & 171.7 & 144.6 & $(35.1)$ INS \\
V & 0.985 & 0.083 & -75.5 & 365.7 & 338.5 & 82.2 \\
W & 0.988 & 0.083 & -75.5 & 366.8 & 339.6 & 82.5 \\
X & 0.990 & 0.084 & -75.1 & 362.5 & 335.3 & 81.4 \\
Y & 0.988 & 0.081 & -75.6 & 376.0 & 348.9 & 84.7 \\
DUM & 0.998 & 0.930 & 3.6 & -2.14 & & \\
& & & & $\eta=21$ & $\eta=21$ & $\eta=21$ \\
& & & & $\bar{x}=364.7$ & $\bar{x}=336.5$ & $\bar{x}=81.7$ \\
& & & & $s=9.62$ & $s=9.62$ & $s=2.35$ \\
& & & & $\sigma=9.39$ & $\sigma=9.40$ & $\sigma=84.7$ \\
\hline $\mathrm{INS}$ & & & & & &
\end{tabular}

INS $=$ not used for these calculations 
Box 3. Methanol, not nulled.

$T=20.9^{\circ} \mathrm{C}, C_{\mathrm{D}}=27.2 \mathrm{pF} . C_{\text {air }}=4.2 \mathrm{pF}$.

\begin{tabular}{lcccccc} 
Probe 1 & $\begin{array}{l}V_{\text {ref }} \\
(V)\end{array}$ & $\begin{array}{c}V_{\text {div }} \\
(V)\end{array}$ & $\begin{array}{c}V_{\text {ph }} \\
(\text { degrees })\end{array}$ & $\begin{array}{c}C \\
(p F)\end{array}$ & $\begin{array}{c}C-C_{D} \\
(p F)\end{array}$ & $\varepsilon_{\text {methanol }}$ \\
\hline DUM & 0.985 & 0.672 & -35.4 & 27.0 & - & - \\
A & 0.991 & 0.234 & -67.2 & 124.3 & 97.1 & 23.0 \\
B & 0.991 & 0.239 & -67.0 & 121.5 & 94.3 & 22.3 \\
C & 0.991 & 0.235 & -67.2 & 123.7 & 96.5 & 22.3 \\
D & 0.991 & 0.237 & -67.0 & 122.5 & 95.3 & 22.6 \\
E & 0.991 & 0.246 & -66.6 & 117.7 & 90.5 & 21.4 \\
F & 0.985 & 0.238 & -66.6 & 120.9 & 93.7 & 22.2 \\
G & 0.989 & 0.242 & -66.6 & 119.4 & 92.2 & 21.8 \\
H & & & & & & \\
J & 0.989 & 0.236 & -67.0 & 122.8 & 95.6 & 22.7 \\
K & 0.987 & 0.223 & -67.0 & 124.1 & 96.9 & 23.0 \\
L & 0.982 & 0.235 & -66.7 & 122.2 & 95.0 & 22.5 \\
M & 0.992 & 0.287 & -64.7 & 99.5 & 72.3 & $(17.0)$ INS \\
N & 0.991 & 0.234 & -67.3 & 124.3 & 97.2 & 23.0 \\
O & 0.990 & 0.238 & -66.9 & 121.8 & 94.6 & 22.4 \\
P & 0.991 & 0.230 & -67.4 & 126.6 & 99.4 & 23.6 \\
R & 0.990 & 0.237 & -67.0 & 123.4 & 96.2 & 22.8 \\
S & 0.990 & 0.235 & -67.1 & 123.5 & 96.3 & 22.8 \\
T & 0.991 & 0.238 & -67.0 & 122.0 & 94.8 & 22.5 \\
U & 0.992 & 0.287 & -64.8 & 99.5 & 72.4 & $(17.1)$ INS \\
V & 0.991 & 0.236 & -67.2 & 123.2 & 96.0 & 22.8 \\
W & 0.991 & 0.241 & -69.9 & 120.4 & 93.2 & 22.1 \\
X & & & & & & \\
Y & 0.990 & 0.236 & -67.1 & 123.0 & 95.8 & 22.1 \\
DUM & 0.999 & 0.682 & -35.9 & 27.3 & & \\
& & & & $\eta=19$ & $\eta=19$ & $\eta=19$ \\
& & & & $\bar{x}=122.5$ & $\bar{x}=95.3$ & $\bar{x}=22.6$ \\
& & & & $s=2.00$ & $s=2.00$ & $s=0.49$ \\
& & & & $\sigma=1.94$ & $\sigma=1.94$ & $\sigma=0.48$ \\
\hline $\mathrm{INS}$ & & & & & &
\end{tabular}

INS $=$ not used for these calculations 
Box 4. Methanol, nulled. $C_{\mathrm{D}}=2.29 \mathrm{pF}$.

$$
C_{\text {air }}=2.99 \mathrm{pF} \text {. }
$$

\begin{tabular}{llccccc} 
Probe 1 & $\begin{array}{l}V_{\text {ref }} \\
(V)\end{array}$ & $\begin{array}{c}V_{\text {div }} \\
(V)\end{array}$ & $\begin{array}{c}V_{p h} \\
(\text { degrees })\end{array}$ & $\begin{array}{c}C \\
(p F)\end{array}$ & $\begin{array}{c}C-C_{D} \\
(p F)\end{array}$ & $\varepsilon_{\text {methanol }}$ \\
\hline DUM & 0.991 & 0.920 & 4.1 & -2.45 & - & - \\
A & 0.994 & 0.339 & -63.4 & 83.4 & 85.7 & 28.7 \\
B & 0.993 & 0.345 & -63.2 & 281.8 & 84.1 & 28.1 \\
C & 0.994 & 0.331 & -63.9 & 85.8 & 88.1 & 29.5 \\
D & 0.994 & 0.337 & -63.6 & 284.1 & 86.4 & 28.9 \\
E & 0.991 & 0.356 & -62.4 & 78.8 & 81.0 & 27.1 \\
F & 0.994 & 0.336 & -63.6 & 284.3 & 86.6 & 29.0 \\
G & 0.993 & 0.337 & -63.5 & 83.9 & 86.2 & 28.8 \\
H & 0.994 & 0.337 & -63.6 & 884.1 & 86.4 & 28.9 \\
J & 0.993 & 0.336 & -63.7 & 284.3 & 86.6 & 29.0 \\
K & 0.993 & 0.333 & -63.8 & 85.2 & 87.4 & 29.2 \\
L & 0.993 & 0.334 & -63.8 & 84.9 & 87.2 & 29.2 \\
M & 0.992 & 0.425 & -59.3 & 63.9 & 66.2 & $(22.1)$ INS \\
N & 0.993 & 0.332 & -63.9 & 885.5 & 87.8 & 29.4 \\
O & 0.993 & 0.339 & -63.5 & 883.4 & 85.7 & 28.7 \\
P & 0.987 & 0.326 & -63.2 & 886.0 & 88.3 & 29.5 \\
R & 0.993 & 0.338 & -63.5 & 883.7 & 86.0 & 28.8 \\
S & 0.992 & 0.337 & -63.6 & 83.9 & 80.2 & 28.8 \\
T & 0.991 & 0.337 & -64.8 & 84.7 & 87.0 & 29.1 \\
U & 0.990 & 0.426 & -58.6 & 663.1 & 65.4 & $(21.9)$ INS \\
V & 0.993 & 0.335 & -63.7 & 84.6 & 86.9 & 29.5 \\
W & 0.992 & 0.340 & -63.4 & 83.0 & 85.3 & 28.5 \\
X & - & - & - & - & - & - \\
Y & 0.992 & 0.333 & -64.0 & 885.2 & 87.5 & 29.3 \\
DUM & 0.998 & 0.930 & 3.6 & -2.14 & & \\
& & & & $\eta=20$ & $\eta=20$ & $\eta=20$ \\
& & & & $\bar{x}=84.0$ & $\bar{x}=86.3$ & $\bar{x}=28.9$ \\
& & & & $s=1.59$ & $s=1.60$ & $s=0.54$ \\
& & & & $\sigma=1.55$ & $\sigma=1.56$ & $\sigma=0.52$ \\
\hline $\mathrm{NS}$ & & & & & &
\end{tabular}

INS $=$ not used for these calculations 


\section{APPENDIX C: RAW DATA FROM GSB SITE FIELD TESTS}

Real dielectric constant calculations for the CRREL test site measurements using SOIL CALC in EUREKA

$$
\begin{aligned}
C_{\text {cable }} & =1.04 \mathrm{pF} \\
C_{\text {air }} & =3.5 \mathrm{pF} \\
\text { Insulation } & =63.2 \mathrm{pF}
\end{aligned}
$$

Checked probe in water (insulated and sealed)

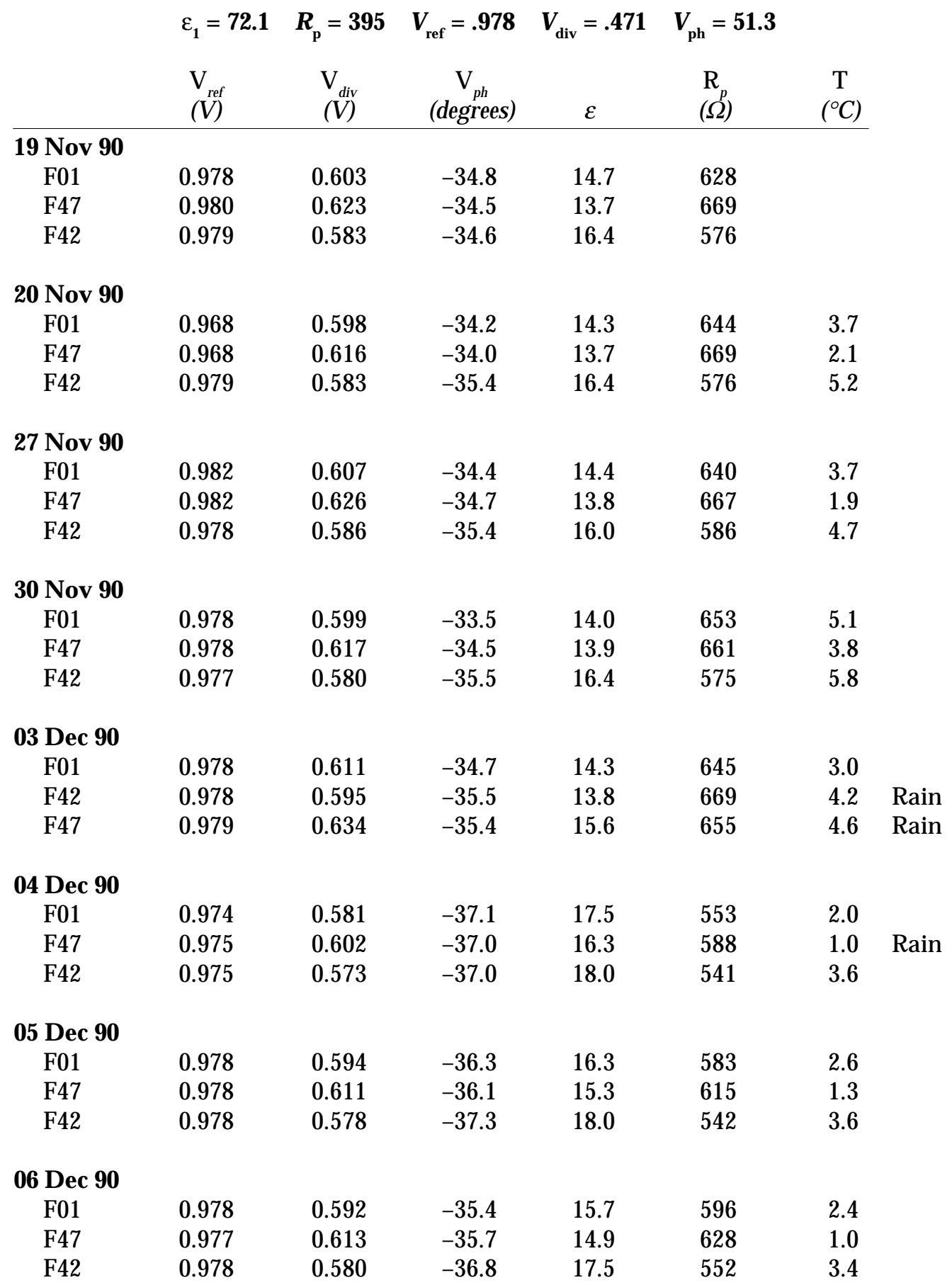




\begin{tabular}{|c|c|c|c|c|c|c|}
\hline & $\begin{array}{l}\mathrm{V}_{\text {ref }} \\
(V)\end{array}$ & $\begin{array}{l}\mathrm{V}_{d i v} \\
(V)\end{array}$ & $\begin{array}{c}\mathrm{V}_{\text {ph }} \\
\text { (degrees) }\end{array}$ & $\varepsilon$ & $\begin{array}{l}\mathrm{R}_{p} \\
(\Omega)\end{array}$ & $\begin{array}{c}\mathrm{T} \\
\left({ }^{\circ} \mathrm{C}\right)\end{array}$ \\
\hline \multicolumn{7}{|c|}{07 Dec 90} \\
\hline F01 & 0.976 & 0.595 & -33.8 & 14.4 & 640 & 2.0 \\
\hline F47 & 0.976 & 0.615 & -34.8 & 14.1 & 652 & 0.5 \\
\hline F42 & 0.976 & 0.581 & -36.3 & 17.0 & 564 & 3.0 \\
\hline \multicolumn{7}{|c|}{10 Dec 90} \\
\hline F01 & 0.976 & 0.600 & -35.3 & 15.2 & 614 & 1.7 \\
\hline F47 & 0.974 & 0.615 & -35.3 & 14.4 & 643 & 0.7 \\
\hline F42 & 0.977 & 0.585 & -36.3 & 16.8 & 569 & 2.9 \\
\hline \multicolumn{7}{|c|}{11 Dec 90} \\
\hline F01 & 0.975 & 0.601 & -33.9 & 14.1 & 650 & 1.3 \\
\hline F47 & 0.975 & 0.625 & -34.0 & 13.2 & 692 & 0.1 \\
\hline $\mathrm{F} 42$ & 0.976 & 0.587 & -35.8 & 16.2 & 582 & 2.8 \\
\hline \multicolumn{7}{|c|}{12 Dec 90} \\
\hline F01 & 0.974 & 0.581 & -37.1 & 17.5 & 553 & 2.0 \\
\hline F47 & 0.975 & 0.602 & -37.0 & 16.3 & 588 & 1.0 \\
\hline F42 & 0.975 & 0.573 & -37.0 & 18.0 & 541 & 3.6 \\
\hline \multicolumn{7}{|c|}{13 Dec 90} \\
\hline F01 & 0.978 & 0.609 & -34.8 & 14.5 & 639 & 1.2 \\
\hline F47 & 0.980 & 0.634 & -33.5 & 12.7 & 717 & 0.1 \\
\hline F42 & 0.977 & 0.592 & -35.1 & 15.5 & 603 & 2.2 \\
\hline \multicolumn{7}{|c|}{14 Dec 90} \\
\hline F01 & 0.976 & 0.608 & -34.7 & 14.4 & 642 & 1.2 \\
\hline F47 & 0.977 & 0.636 & -33.6 & 12.6 & 722 & 0.1 \\
\hline F42 & 0.977 & 0.591 & -35.1 & 15.5 & 601 & 2.3 \\
\hline \multicolumn{7}{|c|}{17 Dec 90} \\
\hline F01 & 0.984 & 0.618 & -34.7 & 14.2 & 651 & 1.8 \\
\hline F47 & 0.981 & 0.638 & -33.2 & 12.4 & 733 & 0.2 \\
\hline F42 & 0.984 & 0.602 & -35.0 & 15.1 & 615 & 2.2 \\
\hline \multicolumn{7}{|c|}{18 Dec 90} \\
\hline F01 & 0.978 & 0.616 & -34.5 & 14.0 & 659 & 0.8 \\
\hline F47 & 0.977 & 0.632 & -33.2 & 12.5 & 726 & 0.2 \\
\hline F42 & 0.978 & 0.602 & -34.9 & 14.8 & 624 & 2.1 \\
\hline \multicolumn{7}{|c|}{19 Dec 90} \\
\hline F01 & 0.978 & 0.615 & -34.5 & 14.0 & 657 & 0.9 \\
\hline F47 & 0.977 & 0.632 & -33.2 & 12.5 & 727 & 0.1 \\
\hline F42 & 0.979 & 0.600 & -34.7 & 14.8 & 624 & 1.7 \\
\hline \multicolumn{7}{|c|}{20 Dec 90} \\
\hline F01 & 0.980 & 0.616 & -34.6 & 14.1 & 654 & 0.8 \\
\hline F47 & 0.980 & 0.632 & -33.5 & 12.8 & 714 & 0.1 \\
\hline F42 & 0.981 & 0.605 & -35.4 & 15.2 & 616 & 1.9 \\
\hline
\end{tabular}




\begin{tabular}{|c|c|c|c|c|c|c|}
\hline & $\begin{array}{l}\mathrm{V}_{\text {ref }} \\
(V)\end{array}$ & $\begin{array}{l}\mathrm{V}_{\text {div }} \\
(V)\end{array}$ & $\begin{array}{c}\mathrm{V}_{\text {ph }} \\
\text { (degrees) }\end{array}$ & $\varepsilon$ & $\begin{array}{l}\mathrm{R}_{p} \\
(\Omega)\end{array}$ & $\begin{array}{c}\mathrm{T} \\
\left({ }^{\circ} \mathrm{C}\right)\end{array}$ \\
\hline \multicolumn{7}{|c|}{21 Dec 90} \\
\hline F01 & 0.984 & 0.622 & -34.9 & 14.2 & 653 & 0.7 \\
\hline F47 & 0.983 & 0.638 & -33.8 & 12.8 & 713 & 0.1 \\
\hline F42 & 0.983 & 0.603 & -35.1 & 15.1 & 616 & 1.8 \\
\hline \multicolumn{7}{|c|}{26 Dec 90} \\
\hline F01 & 0.980 & 0.603 & -34.9 & 14.9 & 624 & 1.1 \\
\hline F47 & 0.979 & 0.620 & -34.0 & 13.5 & 678 & 0.1 \\
\hline F42 & 0.979 & 0.585 & -35.7 & 16.5 & 578 & 1.9 \\
\hline \multicolumn{7}{|c|}{31 Dec 90} \\
\hline F01 & 0.978 & 0.608 & -34.6 & 14.4 & 642 & 0.5 \\
\hline F47 & 0.978 & 0.658 & -29.5 & 9.8 & 941 & 0.1 \\
\hline $\mathrm{F} 42$ & 0.978 & 0.586 & -36.1 & 16.6 & 573 & 1.1 \\
\hline \multicolumn{7}{|c|}{02 Jan 91} \\
\hline F01 & 0.977 & 0.611 & -33.6 & 13.6 & 674 & 0.3 \\
\hline F47 & 0.979 & 0.696 & -26.2 & 7.6 & 1299 & 0.1 \\
\hline F42 & 0.976 & 0.586 & -35.1 & 15.8 & 573 & 1.3 \\
\hline \multicolumn{7}{|c|}{03 Jan 91} \\
\hline F01 & 0.979 & .610 & -34.1 & 14.0 & 657 & 0.3 \\
\hline F47 & 0.979 & 00.688 & -27.0 & 8.0 & 1199 & 0.7 \\
\hline F42 & 0.979 & 0.591 & -35.1 & 15.6 & 600 & 1.2 \\
\hline \multicolumn{7}{|c|}{04 Jan 91} \\
\hline F01 & 0.977 & 0.612 & -33.8 & 13.7 & 671 & 0.1 \\
\hline F47 & 0.977 & 0.702 & -26.2 & 7.5 & 1322 & 1.7 \\
\hline F42 & 0.977 & 0.592 & -34.9 & 15.3 & 608 & 1.1 \\
\hline \multicolumn{7}{|c|}{ 07 Jan 91} \\
\hline F01 & 0.976 & 0.620 & -33.0 & 12.8 & 710 & 0.1 \\
\hline F47 & 0.976 & 0.699 & -26.1 & 7.5 & 1322 & -1.8 \\
\hline F42 & 0.976 & 0.597 & -34.8 & 14.3 & 643 & 0.9 \\
\hline \multicolumn{7}{|c|}{08 Jan 91} \\
\hline F01 & 0.976 & 0.639 & -30.4 & 10.7 & 852 & -0.7 \\
\hline F47 & 0.976 & 0.706 & -25.7 & 7.2 & 1391 & -2.5 \\
\hline F42 & 0.976 & 0.599 & -33.5 & 14.0 & 655 & 0.5 \\
\hline \multicolumn{7}{|c|}{09 Jan 91} \\
\hline F01 & 0.977 & 0.693 & -26.0 & 7.5 & 1314 & -1.2 \\
\hline F47 & 0.976 & 0.715 & -25.3 & 6.9 & 1467 & -3.3 \\
\hline F42 & 0.977 & 0.604 & -33.3 & 13.7 & 669 & 0.3 \\
\hline \multicolumn{7}{|c|}{10 Jan 91} \\
\hline F01 & 0.966 & 0.690 & -26.2 & 7.5 & 1309 & -0.9 \\
\hline F47 & 0.977 & 0.722 & -25.9 & 7.0 & 1419 & -2.3 \\
\hline F42 & 0.977 & 0.617 & -33.7 & 13.4 & 682 & 0.3 \\
\hline
\end{tabular}




\begin{tabular}{ccccrrr} 
& $\begin{array}{c}\mathrm{V}_{\text {ref }} \\
(V)\end{array}$ & $\begin{array}{c}\mathrm{V}_{\text {div }} \\
(V)\end{array}$ & $\begin{array}{c}\mathrm{V}_{p h} \\
(\text { degrees })\end{array}$ & \multicolumn{1}{c}{$\varepsilon$} & $\begin{array}{c}\mathrm{R}_{p} \\
(\Omega)\end{array}$ & $\begin{array}{c}\mathrm{T} \\
\left({ }^{\circ} \mathrm{C}\right)\end{array}$ \\
\hline 11 Jan 91 & & & & & & \\
F01 & 0.966 & 0.692 & -26.0 & 7.4 & 1336 & -0.8 \\
F47 & 0.966 & 0.708 & -25.6 & 7.0 & 1434 & -2.3 \\
F42 & 0.966 & 0.616 & -32.1 & 12.2 & 745 & 0.0
\end{tabular}

14 Jan 91; about 12 in. of snow over the weekend.

$\begin{array}{lrrlrrr}\text { F01 } & 0.966 & 0.686 & -25.58 & 7.3 & 1370 & -0.6 \\ \text { F47 } & 0.966 & 0.703 & -25.5 & 7.1 & 1428 & -2.0 \\ \text { F42 } & 0.965 & 0.619 & -30.5 & 11.2 & 818 & 0.2\end{array}$

$\begin{array}{crrrrrr}\text { 16 Jan 91 } & & & & & & \\ \text { F01 } & 0.975 & 0.690 & -25.8 & 7.5 & 1330 & -0.7 \\ \text { F47 } & 0.974 & 0.701 & -25.6 & 7.2 & 1390 & -0.6 \\ \text { F42 } & 0.975 & 0.630 & -30.1 & 10.8 & 847 & -0.3\end{array}$

$\begin{array}{crrrrrr}\text { 17 Jan 91 } & & & & & & \\ \text { F01 } & 0.980 & 0.686 & -26.4 & 7.9 & 1246 & -0.6 \\ \text { F47 } & 0.978 & 0.690 & -26.6 & 7.9 & 1244 & -0.4 \\ \text { F42 } & 0.978 & 0.631 & -30.2 & 10.9 & 840 & -0.3\end{array}$

$\begin{array}{crrrrrr}\text { 21 Jan 91 } & & & & & & \\ \text { F01 } & 0.973 & 0.674 & -26.5 & 8.1 & 1205 & -0.6 \\ \text { F47 } & 0.974 & 0.703 & -25.5 & 7.2 & 1408 & -1.8 \\ \text { F42 } & 0.974 & 0.623 & -30.9 & 11.4 & 796 & -0.1 \\ & & & & & & \\ \text { 23 Jan 91 } & & & & & & \\ \text { F01 } & 0.977 & 0.719 & -24.8 & 6.7 & 1542 & -1.8 \\ \text { F47 } & 0.978 & 0.729 & -24.8 & 6.6 & 1575 & -5.9 \\ \text { F42 } & 0.977 & 0.676 & -26.3 & 8.0 & 1231 & -1.1\end{array}$

$\begin{array}{ccccccc}\text { 24 Jan 91 } & & & & & & \\ \text { F01 } & 0.976 & 0.715 & -24.8 & 6.7 & 1530 & -2.9 \\ \text { F47 } & 0.976 & 0.721 & -24.8 & 6.7 & 1552 & -4.2 \\ \text { F42 } & 0.976 & 0.687 & -25.2 & 7.3 & 1384 & -0.8\end{array}$

$\begin{array}{ccccccc}\text { 28 Jan 91 } & & & & & & \\ \text { F01 } & 0.977 & 0.718 & -24.5 & 6.6 & 1578 & -3.2 \\ \text { F47 } & 0.977 & 0.722 & -25.1 & 6.8 & 1514 & -3.1 \\ \text { F42 } & 0.977 & 0.711 & -23.7 & 6.4 & 1667 & -2.2\end{array}$

$\begin{array}{ccccccc}\text { 29 Jan 91 } & & & & & & \\ \text { F01 } & 0.974 & 0.716 & -24.1 & 6.6 & 1593 & -3.5 \\ \text { F47 } & 0.975 & 0.723 & -25.0 & 6.7 & 1536 & -4.9 \\ \text { F42 } & 0.974 & 0.708 & -23.8 & 6.4 & 1649 & -2.1\end{array}$

$\begin{array}{ccccccc}\text { 30 Jan 91 } & & & & & & \\ \text { F01 } & 0.975 & 0.712 & -24.6 & 6.7 & 1548 & -2.2 \\ \text { F47 } & 0.974 & 0.715 & -25.1 & 6.8 & 1497 & -3.1 \\ \text { F42 } & 0.975 & 0.704 & -23.9 & 6.5 & 1616 & -1.7\end{array}$




\begin{tabular}{|c|c|c|c|c|c|c|}
\hline & $\begin{array}{l}\mathrm{V}_{\text {ref }} \\
(V)\end{array}$ & $\begin{array}{l}\mathrm{V}_{\text {div }} \\
(V)\end{array}$ & $\begin{array}{c}\mathrm{V}_{p h} \\
\text { (degrees) }\end{array}$ & $\varepsilon$ & $\begin{array}{l}\mathrm{R}_{p} \\
(\Omega) \\
\end{array}$ & $\begin{array}{c}\mathrm{T} \\
\left({ }^{\circ} \mathrm{C}\right) \\
\end{array}$ \\
\hline \multicolumn{7}{|c|}{31 Jan 91} \\
\hline F01 & 0.973 & 0.703 & -25.0 & 7.0 & 1470 & -1.3 \\
\hline F47 & 0.973 & 0.707 & -25.6 & 7.1 & 1413 & -1.3 \\
\hline F42 & 0.972 & 0.701 & -24.1 & 6.6 & 1584 & -1.0 \\
\hline \multicolumn{7}{|c|}{04 Feb 91} \\
\hline F01 & 0.980 & 0.707 & -25.2 & 7.0 & 1442 & -1.2 \\
\hline F47 & 0.981 & 0.712 & -25.7 & 7.2 & 1399 & -1.2 \\
\hline F42 & 0.979 & 0.700 & -24.1 & 6.7 & 1561 & -1.1 \\
\hline \multicolumn{7}{|c|}{06 Feb 91} \\
\hline F01 & 0.980 & 0.704 & -25.7 & 7.3 & 1375 & -1.0 \\
\hline F47 & 0.980 & 0.701 & -26.1 & 7.5 & 1323 & -0.9 \\
\hline F42 & 0.980 & 0.698 & -24.6 & 6.9 & 1485 & -0.9 \\
\hline \multicolumn{7}{|c|}{07 Feb 91} \\
\hline F01 & 0.980 & 0.696 & -22.0 & 7.5 & 1317 & -0.8 \\
\hline F47 & 0.979 & 0.695 & -26.6 & 7.8 & 1257 & -0.7 \\
\hline F42 & 0.981 & 0.693 & -25.2 & 7.3 & 1392 & -0.7 \\
\hline \multicolumn{7}{|c|}{08 Feb 91} \\
\hline F01 & 0.977 & 0.695 & -26.1 & 7.6 & 1310 & -0.6 \\
\hline F47 & 0.976 & 0.692 & -26.8 & 7.9 & 1235 & -0.5 \\
\hline F42 & 0.977 & 0.688 & -25.3 & 7.3 & 1373 & -0.5 \\
\hline \multicolumn{7}{|c|}{13 Feb 91} \\
\hline F01 & 0.976 & 0.716 & -24.7 & 6.7 & 1547 & -3.7 \\
\hline F47 & 0.977 & 0.722 & -25.2 & 6.8 & 1501 & -4.0 \\
\hline F42 & 0.974 & 0.694 & -24.3 & 6.8 & 1525 & -1.7 \\
\hline \multicolumn{7}{|c|}{15 Feb 91} \\
\hline F01 & 0.977 & 0.709 & -24.9 & 6.9 & 1493 & -1.4 \\
\hline F47 & 0.978 & 0.714 & -25.6 & 7.1 & 1424 & -1.7 \\
\hline F42 & 0.976 & 0.695 & -24.3 & 6.8 & 1523 & -0.7 \\
\hline \multicolumn{7}{|c|}{19 Feb 91} \\
\hline F01 & 0.972 & 0.706 & -24.6 & 6.8 & 1534 & -2.0 \\
\hline F47 & 0.972 & 0.706 & -25.2 & 7.0 & 1459 & -2.2 \\
\hline F42 & 0.973 & 0.699 & -23.9 & 6.6 & 1602 & -1.4 \\
\hline \multicolumn{7}{|c|}{21 Feb 91} \\
\hline F01 & 0.972 & 0.696 & -25.3 & 7.2 & 1412 & -1.0 \\
\hline F47 & 0.971 & 0.697 & -26.1 & 7.4 & 1330 & -1.0 \\
\hline F42 & 0.971 & 0.691 & -24.2 & 6.8 & 1535 & -0.9 \\
\hline \multicolumn{7}{|c|}{26 Feb 91} \\
\hline F01 & 0.960 & 0.706 & -24.5 & 6.6 & 1580 & -3.3 \\
\hline F47 & 0.960 & 0.711 & -25.3 & 6.8 & 1495 & -4.3 \\
\hline F42 & 0.960 & 0.697 & -23.9 & 6.5 & 1630 & -2.0 \\
\hline
\end{tabular}




\begin{tabular}{|c|c|c|c|c|c|c|}
\hline & $\begin{array}{l}\mathrm{V}_{\text {ref }} \\
(V)\end{array}$ & $\begin{array}{l}\mathrm{V}_{\text {div }} \\
(V)\end{array}$ & $\begin{array}{c}\mathrm{V}_{\text {ph }} \\
\text { (degrees) }\end{array}$ & $\varepsilon$ & $\begin{array}{c}\mathrm{R}_{p} \\
(\Omega)\end{array}$ & $\begin{array}{c}\mathrm{T} \\
\left({ }^{\circ} \mathrm{C}\right)\end{array}$ \\
\hline \multicolumn{7}{|c|}{04 Mar 91} \\
\hline F01 & 0.976 & 0.693 & -26.0 & 7.5 & 1316 & -0.8 \\
\hline F47 & 0.975 & 0.688 & -26.8 & 7.9 & 1225 & -0.4 \\
\hline F42 & 0.977 & 0.693 & -24.9 & 7.1 & 1437 & -0.7 \\
\hline \multicolumn{7}{|c|}{05 Mar 91} \\
\hline F01 & 0.996 & 0.709 & -24.2 & 6.6 & 1589 & -0.6 \\
\hline F47 & 0.974 & 0.687 & -26.7 & 7.9 & 1234 & -0.5 \\
\hline F42 & 0.975 & 0.700 & -25.3 & 7.1 & 1419 & -0.5 \\
\hline \multicolumn{7}{|c|}{06 Mar 91} \\
\hline F01 & 0.980 & 0.690 & -25.8 & 7.6 & 1318 & -0.7 \\
\hline F47 & 0.981 & 0.690 & -27.1 & 8.1 & 1194 & -0.6 \\
\hline F42 & 0.980 & 0.915 & -25.0 & 7.2 & 1411 & -0.6 \\
\hline \multicolumn{7}{|c|}{07 Mar 91} \\
\hline F01 & 0.979 & 0.700 & -26.7 & 7.7 & 1263 & -0.6 \\
\hline F47 & 0.977 & 0.685 & -27.1 & 8.1 & 1186 & -0.2 \\
\hline F42 & 0.978 & 0.693 & -25.3 & 7.3 & 1388 & -0.4 \\
\hline \multicolumn{7}{|c|}{$22 \operatorname{Mar} 91$} \\
\hline F01 & 0.973 & 0.674 & -26.9 & 8.2 & 1179 & -0.5 \\
\hline F47 & 0.970 & 0.684 & -27.8 & 8.4 & 1140 & -0.4 \\
\hline F42 & 0.972 & 0.658 & -26.8 & 8.4 & 1141 & -0.4 \\
\hline \multicolumn{7}{|c|}{26 Mar 91} \\
\hline F01 & 0.978 & 0.681 & -25.3 & 7.5 & 1347 & -0.6 \\
\hline F47 & 0.978 & 0.677 & -28.3 & 8.8 & 1067 & -0.6 \\
\hline F42 & 0.979 & 0.666 & -28.3 & 9.1 & 1036 & -0.6 \\
\hline \multicolumn{7}{|c|}{27 Mar 91} \\
\hline F01 & 0.974 & 0.668 & -27.4 & 8.6 & 1117 & -0.3 \\
\hline F47 & 0.973 & 0.667 & -28.0 & 8.8 & 1071 & -0.3 \\
\hline F42 & 0.974 & 0.646 & -28.7 & 9.6 & 965 & -0.2 \\
\hline \multicolumn{7}{|c|}{28 Mar 91} \\
\hline F01 & 0.973 & 0.681 & -28.2 & 8.6 & 1095 & -0.4 \\
\hline F47 & 0.973 & 0.643 & -31.8 & 11.3 & 804 & 0.1 \\
\hline F42 & 0.974 & 0.631 & -30.5 & 11.0 & 832 & -0.3 \\
\hline \multicolumn{7}{|c|}{01 Apr 91} \\
\hline F01 & 0.973 & 0.655 & -28.4 & 9.3 & 1010 & -0.3 \\
\hline F47 & 0.973 & 0.599 & -36.6 & 16.1 & 592 & -0.1 \\
\hline F42 & 0.973 & 0.613 & -31.8 & 12.3 & 740 & -0.2 \\
\hline \multicolumn{7}{|c|}{07 Apr 91} \\
\hline F01 & 0.980 & 0.591 & -36.0 & 16.3 & 582 & 1.2 \\
\hline F47 & 0.978 & 0.597 & -36.4 & 16.2 & 586 & 5.9 \\
\hline F42 & 0.979 & 0.974 & -35.0 & 15.4 & 607 & 0.2 \\
\hline
\end{tabular}




\begin{tabular}{|c|c|c|c|c|c|c|}
\hline & $\begin{array}{l}\mathrm{V}_{r e f} \\
(V)\end{array}$ & $\begin{array}{l}\mathrm{V}_{\text {div }} \\
(V)\end{array}$ & $\begin{array}{c}\mathrm{V}_{p h} \\
\text { (degrees) }\end{array}$ & $\varepsilon$ & $\begin{array}{l}\mathrm{R}_{p} \\
(\Omega)\end{array}$ & $\begin{array}{c}\mathrm{T} \\
\left({ }^{\circ} \mathrm{C}\right)\end{array}$ \\
\hline \multicolumn{7}{|c|}{08 Apr 91} \\
\hline F01 & 0.974 & 0.589 & -35.4 & 15.8 & 595 & 4.5 \\
\hline $\mathrm{F} 47$ & 0.973 & 0.598 & -35.8 & 15.6 & 604 & 7.2 \\
\hline F42 & 0.975 & 0.587 & -35.4 & 15.9 & 591 & 0.6 \\
\hline \multicolumn{7}{|c|}{10 Apr 91} \\
\hline F01 & 0.970 & 0.579 & -35.3 & 16.1 & 584 & 9.4 \\
\hline $\mathrm{F} 47$ & 0.969 & 0.590 & -35.8 & 15.8 & 595 & 8.5 \\
\hline F42 & 0.969 & 0.565 & -35.2 & 16.8 & 563 & 7.7 \\
\hline \multicolumn{7}{|c|}{16 Apr 91} \\
\hline F01 & 0.970 & 0.586 & -35.0 & 15.5 & 602 & 5.8 \\
\hline F47 & 0.972 & 0.595 & -35.9 & 15.7 & 598 & 6.1 \\
\hline F42 & 0.971 & 0.575 & -34.8 & 15.9 & 586 & 5.9 \\
\hline \multicolumn{7}{|c|}{17 Apr 91} \\
\hline F01 & 0.971 & 0.588 & -34.8 & 15.3 & 609 & 6.0 \\
\hline F47 & 0.973 & 0.600 & -35.6 & 15.3 & 611 & 5.4 \\
\hline $\mathrm{F} 42$ & 0.971 & 0.575 & -34.9 & 16.0 & 584 & 5.9 \\
\hline \multicolumn{7}{|c|}{22 Apr 91; heavy rain for past two days. } \\
\hline F01 & 0.970 & 0.583 & -35.3 & 16.9 & 591 & 6.3 \\
\hline F47 & 0.972 & 0.594 & -36.0 & 15.9 & 595 & 6.6 \\
\hline F42 & 0.971 & 0.570 & -35.5 & 16.8 & 564 & 6.0 \\
\hline \multicolumn{7}{|c|}{23 Apr 91} \\
\hline F01 & 0.977 & 0.591 & -35.1 & 15.5 & 601 & 6.7 \\
\hline F47 & 0.979 & 0.601 & -35.6 & 15.4 & 607 & 8.8 \\
\hline $\mathrm{F} 42$ & 0.977 & 0.577 & -35.2 & 16.3 & 576 & 6.5 \\
\hline \multicolumn{7}{|c|}{24 Apr 91} \\
\hline F01 & 0.960 & 0.583 & -34.5 & 14.9 & 618 & 6.8 \\
\hline F47 & 0.962 & 0.596 & -35.4 & 15.0 & 620 & 5.9 \\
\hline $\mathrm{F} 42$ & 0.960 & 0.570 & -34.7 & 15.8 & 591 & 7.1 \\
\hline \multicolumn{7}{|c|}{30 Apr 91} \\
\hline F01 & 0.969 & 0.582 & -35.1 & 15.7 & 594 & 11.2 \\
\hline F47 & 0.972 & 0.588 & -35.7 & 16.0 & 590 & 10.7 \\
\hline F42 & 0.972 & 0.577 & -33.7 & 15.0 & 613 & 10.9 \\
\hline \multicolumn{7}{|c|}{07 May 91} \\
\hline F01 & 0.978 & 0.577 & -35.0 & 16.2 & 578 & 10.1 \\
\hline F47 & 0.980 & 0.593 & -35.6 & 15.6 & 592 & 9.6 \\
\hline F42 & 0.979 & 0.567 & -34.9 & 16.7 & 562 & 9.7 \\
\hline \multicolumn{7}{|c|}{20 May 91} \\
\hline F01 & 0.975 & 0.589 & -32.8 & 13.9 & 656 & - \\
\hline F47 & 0.974 & 0.607 & -31.9 & 12.6 & 723 & - \\
\hline $\mathrm{F} 42$ & 0.975 & 0.583 & -32.0 & 13.6 & 669 & - \\
\hline
\end{tabular}




\begin{tabular}{lcccccc} 
& $\begin{array}{c}\mathrm{V}_{\text {ref }} \\
(V)\end{array}$ & $\begin{array}{c}\mathrm{V}_{\text {div }} \\
(\mathrm{V})\end{array}$ & $\begin{array}{c}\mathrm{V}_{p h} \\
(\text { degrees })\end{array}$ & $\varepsilon$ & $\begin{array}{c}\mathrm{R}_{p} \\
(\Omega)\end{array}$ & $\begin{array}{c}\mathrm{T} \\
\left({ }^{\circ} \mathrm{C}\right)\end{array}$ \\
\hline 24 May 91 & & & & & & \\
F01 & 0.975 & 0.599 & -31.4 & 12.6 & 723 & 16.4 \\
F47 & 0.978 & 0.692 & -30.1 & 10.9 & 840 & 19.2 \\
F42 & 0.977 & 0.598 & -30.7 & 12.2 & 745 & 15.2 \\
& & & & & & \\
28 May 91 & & & & & & \\
F01 & 0.975 & 0.594 & -31.3 & 12.5 & 727 & 17.1 \\
F47 & 0.978 & 0.630 & -30.5 & 11.1 & 824 & 17.9 \\
F42 & 0.976 & 0.602 & -30.3 & 11.8 & 772 & 16.3 \\
& & & & & & \\
29 May 91 & & & & & & \\
F01 & 0.976 & 0.599 & -31.4 & 12.6 & 721 & 17.8 \\
F47 & 0.980 & 0.642 & -30.7 & 10.9 & 839 & 17.9 \\
F42 & 0.977 & 0.600 & -30.4 & 12.0 & 762 & 17.1 \\
& & & & & & \\
29 May 91 Box 1 & & & & & NOTE: \\
F01 & 0.984 & 0.613 & -29.1 & 10.9 & 843 & nulled \\
F47 & 0.986 & 0.644 & -27.6 & 9.3 & 1012 & \\
F42 & 0.983 & 0.611 & -27.9 & 10.3 & 908 & - \\
31 May 91 Box 2 & & & & & \\
F01 & 0.974 & 0.592 & -31.6 & 12.9 & 702 & - \\
F47 & 0.976 & 0.606 & -32.8 & 13.2 & 689 & - \\
F42 & 0.975 & 0.595 & -30.2 & 12.0 & 762 & - \\
03 June 91 Box 3 & & & & & \\
F01 & 0.973 & 0.593 & -32.2 & 13.3 & 685 & 17.2 \\
F47 & 0.974 & 0.618 & -32.4 & 12.5 & 728 & \\
F42 & 0.974 & 0.584 & -31.6 & 13.3 & 685 & 17.9 \\
\hline
\end{tabular}


Public reporting burden for this collection of information is estimated to average 1 hour per response, including the time for reviewing instructions, searching existing data sources, gathering and maintaining the data needed, and completing and reviewing the collection of information. Send comments regarding this burden estimate or any other aspect of this collection of information, including suggestion for reducing this burden, to Washington Headquarters Services, Directorate for Information Operations and Reports, 1215 Jefferson Davis Highway, Suite 1204, Arlington, VA 22202-4302, and to the Office of Management and Budget, Paperwork Reduction Project (0704-0188), Washington, DC 20503.

\begin{tabular}{|l|l|l|}
\hline 1. AGENCY USE ONLY (Leave blank) & $\begin{array}{l}\text { 2. REPORT DATE } \\
\text { January } 1998\end{array}$ & 3. REPORT TYPE AND DATES COVERED \\
\hline
\end{tabular}

4. TITLE AND SUBTITLE

5. FUNDING NUMBERS

Soil Moisture Determinations Using Capacitance Probe Methodology

6. AUTHORS

Ronald T. Atkins, Timothy Pangburn, Roy E. Bates, and Bruce E. Brockett

7. PERFORMING ORGANIZATION NAME(S) AND ADDRESS(ES)

U.S. Army Cold Regions Research and Engineering Laboratory

72 Lyme Road

Hanover, New Hampshire 03755-1290

. PERFORMING ORGANIZATION

REPORT NUMBER

Special Report 98-2

9. SPONSORING/MONITORING AGENCY NAME(S) AND ADDRESS(ES)

10. SPONSORING/MONITORING AGENCY REPORT NUMBER

Office of the Chief of Engineers

Washington, DC 20314-1000

11. SUPPLEMENTARY NOTES

For conversion of SI units to non-SI units of measurement, consult ASTM Standard E380-93, Standard Practice for Use of the International System of Units, published by the American Society for Testing and Materials, 1916 Race St., Philadelphia, Pa. 19103.

12a. DISTRIBUTION/AVAILABILITY STATEMENT 12b. DISTRIBUTION CODE

Approved for public release; distribution is unlimited.

Available from NTIS, Springfield, Virginia 22161

13. ABSTRACT (Maximum 200 words)

Determining soil moisture content by measuring the dielectric constant of the soil is not a new concept. However, determining the dielectric constant by measuring capacitance directly rather than through the use of time domain reflectometry (TDR) systems is a relatively new approach to soil moisture measurements. A unique probe assembly and a readout device that measures voltage drop and phase shift were developed and used for direct capacitance measurements. The capacitance measurement was calibrated using known capacitors and resistors. Soil moisture measurements were calibrated by adding known amounts of distilled water to dry soil enclosed in a known volume. The effect of salinity on the measurement technique was evaluated. Once calibration had been accomplished, actual soil moisture measurements at three test depths through an entire winter's freeze-thaw cycle demonstrated the feasibility of using this capacitance measurement system. The dielectric constants measured using this fixed-frequency capacitance measurement system fall within the same general range as the values obtained using TDR equipment with the Topp or Roth general calibration equations, and they could probably be used directly in these equations after minor corrections. The conclusions drawn from these tests are that this measurement technique could and should be developed as an easier, more economical, and more easily automated and calibrated system for soil moisture measurement.

14. SUBJECT TERMS

Gravimetric sampling

Moisture content

Soil capacitance

17. SECURITY CLASSIFICATION OF REPORT

UNCLASSIFIED
Soil dielectric constants

Soil moisture

Time domain reflectometry

\begin{tabular}{|l|l}
$\begin{array}{l}\text { 18. SECURITY CLASSIFICATION } \\
\text { OF THIS PAGE } \\
\text { UNCLASSIFIED }\end{array}$ & $\begin{array}{l}\text { 19. SECURITY CLASSIFICATION } \\
\text { OF ABSTRACT } \\
\text { UNCLASSIFIED }\end{array}$ \\
\hline
\end{tabular}

UNCLASSIFIED

UNCLASSIFIED

NSN 7540-01-280-5500

15. NUMBER 99 PAGES
16. PRICE CODE
20. LIMITATION OF ABSTRACT
UL

Standard Form 298 (Rev. 2-89) Prescribed by ANSI Std. Z39-18 298-102 